\title{
UCRL-TR-230194
}

LAWRENCE LIVERMORE N A T IO N A L LABORATORY

\section{TNT Prout-Tompkins Kinetics Calibration with PSUADE}

A. P. Wemhoff, H. Hsieh

April 23, 2007 
This document was prepared as an account of work sponsored by an agency of the United States Government. Neither the United States Government nor the University of California nor any of their employees, makes any warranty, express or implied, or assumes any legal liability or responsibility for the accuracy, completeness, or usefulness of any information, apparatus, product, or process disclosed, or represents that its use would not infringe privately owned rights. Reference herein to any specific commercial product, process, or service by trade name, trademark, manufacturer, or otherwise, does not necessarily constitute or imply its endorsement, recommendation, or favoring by the United States Government or the University of California. The views and opinions of authors expressed herein do not necessarily state or reflect those of the United States Government or the University of California, and shall not be used for advertising or product endorsement purposes.

This work was performed under the auspices of the U.S. Department of Energy by University of California, Lawrence Livermore National Laboratory under Contract W-7405-Eng-48. 


\section{Abstract}

We used the code PSUADE to calibrate Prout-Tompkins kinetic parameters for pure recrystallized TNT. The calibration was based on ALE3D simulations of a series of One Dimensional Time to Explosion (ODTX) experiments. The resultant kinetic parameters differed from TNT data points with an average error of $28 \%$, which is slightly higher than the value of $23 \%$ previously calculated using a two-point optimization. The methodology described here provides a basis for future calibration studies using PSUADE. The files used in the procedure are listed in the Appendix. 


\section{Table of Contents}

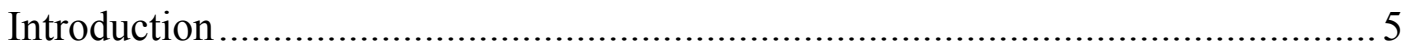

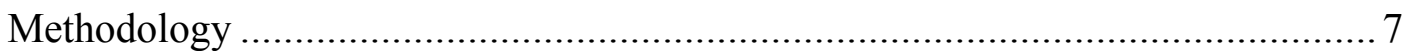

Step 1: Problem Setup ..................................................................... 7

Step 2: Discretization Method ............................................................. 8

Step 3: Response Surface Generation ................................................ 8

Steps 4 and 5: Response Surface Examination.................................... 9

Step 6: Parameter Optimization.................................................... 11

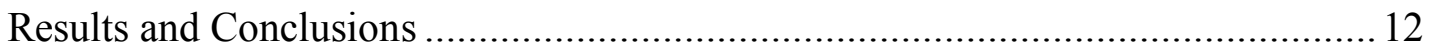

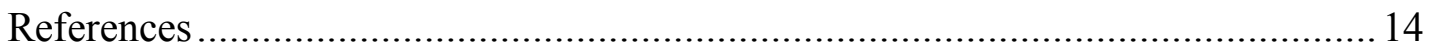

Appendix A: Contents of PSUADE Input File odtxrun.................................. 15

Appendix B: Contents of PSUADE Driver File driver . py ................................. 16

Appendix C: Contents of Batch Script Template b0_odtx.Tmplt ..................... 23

Appendix D: Contents of runodtx . pl ................................................. 24

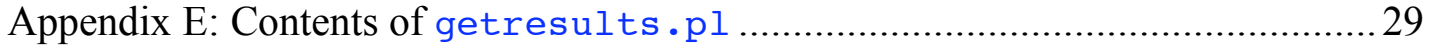

Appendix F: Contents of PSUADE Input File odtxoptminpack ....................... 33

Appendix G: Contents of PSUADE Driver File driveropt.py ......................... 34 
UCRL-TR-230194

\section{Introduction}

A large number of engineering problems involve calibration, which is the adjustment of a set of parameters in a computational model to maximize model agreement with experimental data. These problems are especially relevant in cookoff modeling of of high explosives (HE), for several aspects of these materials are based on empirical models (e.g. material properties and chemical kinetics). Until recently, few options were available for this calibration procedure, although the LLNL code GLO [1] had previously been used to fine-tune HE kinetic parameters [2-4].

Model calibration is different from model validation in that the latter quantifies the belief/confidence in the predictive capability of a computational code through comparison with a set of experimental measurements. One can see that both calibration and validation are often tedious even the problem is well posed. In this study, we only consider calibration. If one defines the discrepancy between model prediction and experimental measurement as an objective function, then the calibration can be achieved simply by minimizing the objective function. In this report, two approaches were used to calibrate the model by minimizing the model discrepancy. The code PSUADE (Problem Solving Environment for Uncertainty Analysis and Design Exploration) provides a useful tool to facilitate this calibration process in that it provides the following advantages:

- Discretization of the $n$-dimensional input surface according to a variety of design schemes (or design of experiments).

- Sensitivity analysis of each of the input parameters on any output parameter

- Multiple output parameters

- Multiple output parameter optimization using the MinPack toolkit.

- Visualization of the response surface

- Batch submission for long-running and multi-processor analyses.

PSUADE has previously been used in complex analyses [5], and this study makes use of only a small portion of the available features in the code. Here, we provide a methodology by which PSUADE was used to adjust the parameters associated with the Prout-Tompkins chemical kinetic model [6],

$$
-\frac{d x}{d t}=A \exp \left(-\frac{E}{R T}\right) x^{n}(1-q x)^{m}
$$

where $x$ is the mass fraction of unreacted HE. For simplicity, we only use a single reaction cookoff model here. The parameter $q$ is very close to one and is therefore commonly written in terms of a parameter $p$ for clarity,

$$
p=-\log _{10}(1-q)
$$

This reaction model states that the rate of reaction is related to the amount of product formed, which would be true if the reaction products attack the unreacted material at a rate faster than it decomposes by itself. 
Calibration of the Prout-Tompkins parameters $A, E, m, n$, and $p$ were performed based on One Dimensional Time to Explosion (ODTX) experimental data [7, 8]. In an ODTX apparatus, the explosive is first pressed into a $1 / 2$ "-diameter sphere, and then the explosive is heated isothermally until ignition. Experimental values were run at 23 temperatures as shown in Figure 1. For the optimization, 7 representative data points were chosen (although all 23 points could be chosen instead if desired).

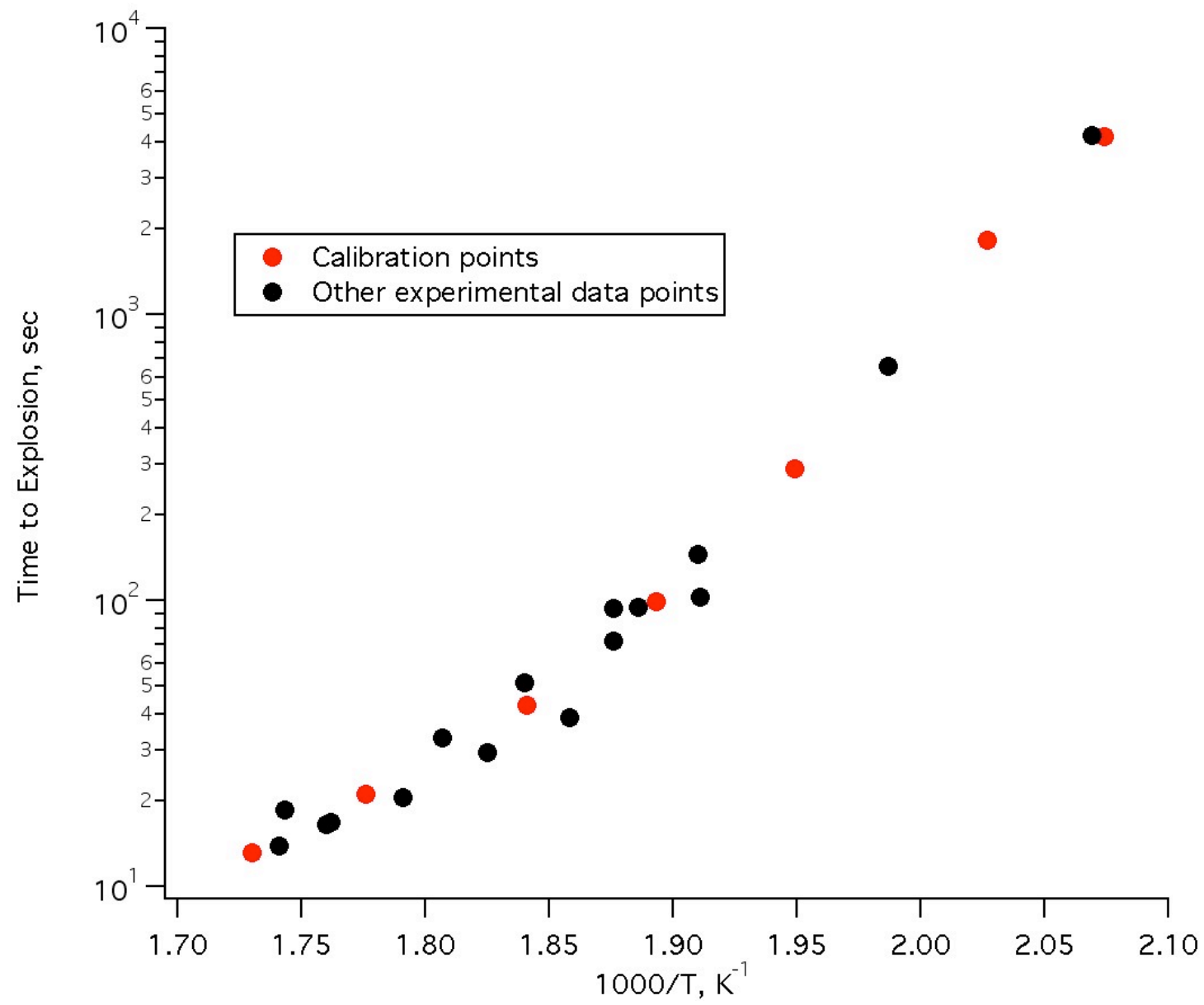

Figure 1. ODTX experimental data for pure recrystallized TNT. Red data points were used for Prout-Tompkins parameter calibration.

The material properties used for pure TNT are provided in Table 1 below. These properties were taken from a previous report [3]. Note that melting and other phase transitions were ignored in the cookoff simulations. 
UCRL-TR-230194

Table 1. TNT properties used in simulations.

\begin{tabular}{|c|c|}
\hline Property & Value \\
\hline Density & $1.654 \mathrm{~g} / \mathrm{cc}$ \\
\hline Energy of reaction & $950 \mathrm{cal} / \mathrm{g}$ \\
\hline Solid heat capacity & $1.37 \mathrm{~J} /(\mathrm{g}-\mathrm{K})$ \\
\hline Solid thermal conductivity & $0.26 \mathrm{~W} /(\mathrm{m}-\mathrm{K})$ \\
\hline Products heat capacity & $1.0 \mathrm{~J} /(\mathrm{g}-\mathrm{K})^{*}$ \\
\hline $\begin{array}{c}\text { Products thermal } \\
\text { conductivity }\end{array}$ & $0.05 \mathrm{~W} /(\mathrm{m}-\mathrm{K})^{*}$ \\
\hline \multicolumn{2}{|c|}{ Estimated value. } \\
\hline
\end{tabular}

\section{Methodology}

To calibrate parameters using PSUADE, the following steps are used:

1. Determine what output is to be optimized, which input parameters should be varied, and what the ranges of the input parameters should be.

2. Choose an appropriate design of experiments for creating the response surface.

3. Run PSUADE to generate the response surface

4. Examine the response surface to ensure that a global minimum lay on the interior of the response surface as opposed to the edges.

5. Examine the sensitivity of the output on each of the input parameters.

6. Run PSUADE with MinPack to optimize the parameters around the minimum on the response surface.

We will now go through each of the above steps to show how the parameters were calibrated.

\section{Step 1: Problem Setup}

The input parameters to be varied are already known in the Prout-Tompkins model: $A, E$, $m, n$, and $p$. PSUADE needs two sets of output parameters to be known: one set with multiple output parameters for MinPack optimization, and one set of a single condensed Figure of Merit (FOM). Here, the FOM is chosen as

$$
F O M=\frac{1}{7} \sum_{i=1}^{7}\left(\ln \left(t_{\text {sim }, i} / t_{\text {expt }, i}\right)\right)^{2}
$$

where $t_{\text {sim }}$ and $t_{\text {exp }}$ are the simulated and experimental times to explosion, respectively. The difference between $t_{s i m, i}$ and $t_{\text {expt,i }}$ for all values of $i$ was chosen as the set with multiple output parameters. Note that the FOM calculated here is slightly different than the one calculated by MinPack, but they are proportional so the trends are identical. 
The ranges for the input parameters are shown in Table 2. These values encompass the values generally encountered when applied for a variety of explosives [3].

Table 2. PSUADE input parameter ranges.

\begin{tabular}{|c|c|c|c|}
\hline Parameter & Units & Minimum Value & Maximum Value \\
\hline$E$ & $\mathrm{cal} / \mathrm{mol}$ & 10000 & 70000 \\
\hline $\ln (A)$ & $\ln \left(\mathrm{us}^{-1}\right)$ & 1 & 40 \\
\hline$m$ & - & 0 & 2 \\
\hline$n$ & - & 0 & 2 \\
\hline$p$ & - & 2 & 9 \\
\hline
\end{tabular}

\section{Step 2: Design of Experiments}

Several design schemes are available in PSUADE. In this study, we chose METIS since the computational cost of an individual run was modest (generally only a few minutes). We originally used 100 runs with METIS to obtain a coarse evenly-spaced response surface, but would later add an additional 100 runs with the randomize and randomize_more options in the PSUADE input file to "fill-in" holes between these discrete points. The perlscript combresults.pl was created to combine output data from multiple PSUADE runs into a single output file.

Appendix A lists the contents of the PSUADE input file odtxrun featuring the input variables and the discretization method.

\section{Step 3: Response Surface Generation}

The run sequence of PSUADE is as follows:

1. PSUADE provides a set of input parameters.

2. The Python script driver . py (Appendix B) reads in the parameters and does the following for the first run (similar approaches apply for other runs):

a. It creates a working directory workdir. 1

b. It copies the files b0_odtx.Tmplt (Appendix C), runodtx.pl (Appendix D), data.txt, and the input parameters file (psuadeApps_ct.in.1) into the newly created working directory. The file b0_odtx.Tmplt is a batch script template file, runodtx.pl is the main perlscript, and data.txt is a listing of ODTX data points for analysis.

c. The batch script bo_odtx is created by copying b0_odtx.Tmplt and replacing strings with the input parameter names. The input variables are fed as command-line arguments to runodtx . pl.

d. The batch script b0_odtx is submitted to the batch system. If there are more than 8 such submissions in the system already, then dependencies are used. This approach is done by the command pstat $>$ stat, opening the file stat, and counting the number of times b0_odtx appears.

3. When the batch process begins, the perlscript runodtx . pl performs the following: 
a. It reads in the ODTX data points from data.txt and calculates the appropriate time step size based on the experimental time-to-explosion.

b. It copies the ALE3D input decks and SAMI file from the base directory into the working directory.

c. For each of the 7 data points, it runs ALE3D using the -def commandline argument to place the input parameters into the simulation. The simulation is run until the simulated time exceeds double the experimental time, the number of time steps exceeds 100,000 , or thermal runaway forces the simulation to terminate.

d. It reads the simulated explosion time from the ALE3D log file and stores it in the output files odt $x-1 \times 10$. res (multiple output) and fom (single output).

4. After all PSUADE data points have been run, the perlscript getresults $\cdot \mathrm{pl}$ (Appendix E) is used to create the PSUADE output files psuadeout (multiple output) and psuadeFom (single output).

\section{Step 4 and 5: Response Surface Examination}

PSUADE has a handy built-in surface plotter feature that allows for examination of the response surface using MATLAB. To use this feature, the two most sensitive input parameters should be used as the axes. The following approach did the sensitivity analysis:

1. Open PSUADE.

5. Type load psuadeFom

2. Type printlevel 3

3. Type rscheck, 0,0

4. PSUADE provides a MARS (Multi-variate Adaptive Regression Spline) importance measure for each input variable (normalized to 100). The two most sensitive parameters are $E(100)$ and $\ln (A)(77)$, while the remaining parameters $m$ (38), $n(12)$, and $p(8)$ are less sensitive. The dominance of $E$ and $\ln (A)$ is not surprising since they are independent of mass fraction, and this feature has been applied in previous studies to "pin" the simulated curve to three points [2-4].

The response surface may then be created using $E$ and $\ln (A)$ as the input parameter axes. PSUADE creates this surface with the following commands:

1. Type rs

2. Use input parameters 1 and 2 for the axes since $E$ is 1 and $\ln (A)$ is 2 here.

3. Let PSUADE set the other nominal values automatically and choose the threshold values.

4. Close PSUADE, open MATLAB, and type matlabrs to create the response surface. 
UCRL-TR-230194
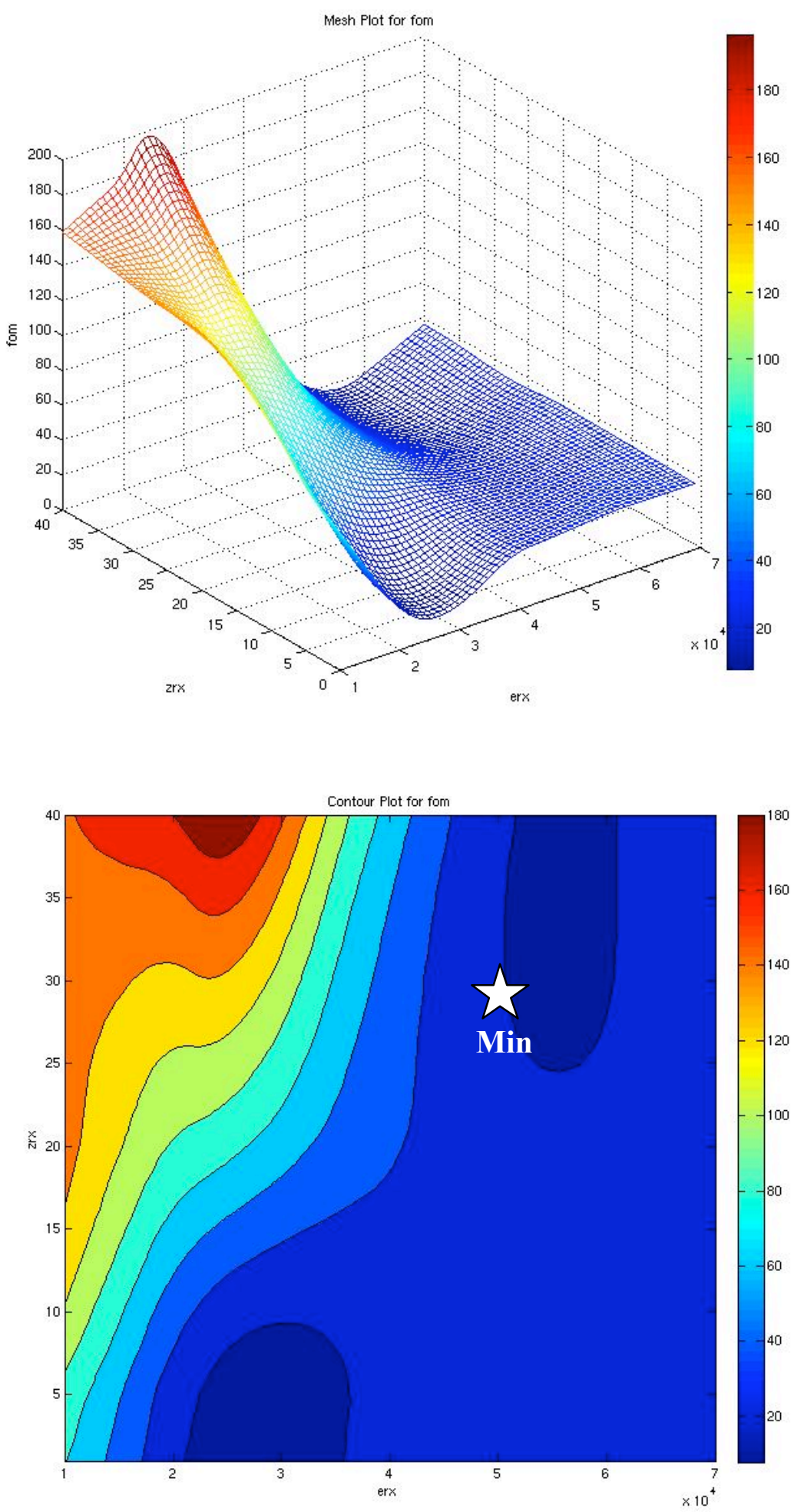

Figure 2. Calculated response surface for $E(e r x)$ and $\ln (A)(z r x)$. The minimum data point lies at 50,372 and 29.38. 
The minimum FOM value can be chosen by running PSUADE and typing the command min. The response surface for this example, along with the minimum value, is shown below in Figure 2. The primary purpose of these plots is to show that the minimum point falls within the range of input values. The plots shown in this figure are merely spline curve fits to the FOM values and therefore do not capture the FOM values themselves. The resultant plots do not contain enough accuracy to allow for visually choosing a minimum value, but rather they provide an overall qualitative depiction of the response surface. For this reason, the actual minimum data point for this example problem does not appear to be located at the minimum location suggested graphically in the figure, although this point is close to the minimum contour in the figure.

\section{Step 6: Parameter Optimization}

The parameters of the Prout-Tompkins cookoff chemical kinetic model are adjusted in two ways. The first approach relies on the response surface that is created from previous steps. The model discrepancy is minimized using the response surface. The second approach involves a point-by-point search. The first approach is a very quick and simple technique but did not provide good results in this case. Therefore, the point-by-point search approach was used. PSUADE performs this optimization in the following manner:

1. The minimum data point on the calculated response surface was used as the starting point for the optimization.

2. The parameter ranges were set as $+/-10 \%$ of the starting point values.

3. Monte Carlo was used as the sampling technique.

4. For each run, the following occurred:

a. PSUADE checked the system every 10 seconds to determine if there are any running jobs. If not, then it grabbed the next data point based on the results of the previous job.

b. PSUADE provided a sample data point, created a working directory, copied files into this directory, and created the batch script b0_odtx in the same manner as for creating the response surface.

c. The batch script was run and the output values were stored.

Appendices $\mathrm{F}$ and $\mathrm{G}$ provide the PSUADE input file odtxoptMinpack and driver file driveropt.py used in the optimization routine.

The perlscript getresults.pl was used to observe how the FOM was changed with each successive run. The lowest value of the FOM occurred in run 64 of 75 as shown in Figure 3. Note that the optimization routine reduced the FOM by a factor of five from the initial starting value. 
UCRL-TR-230194

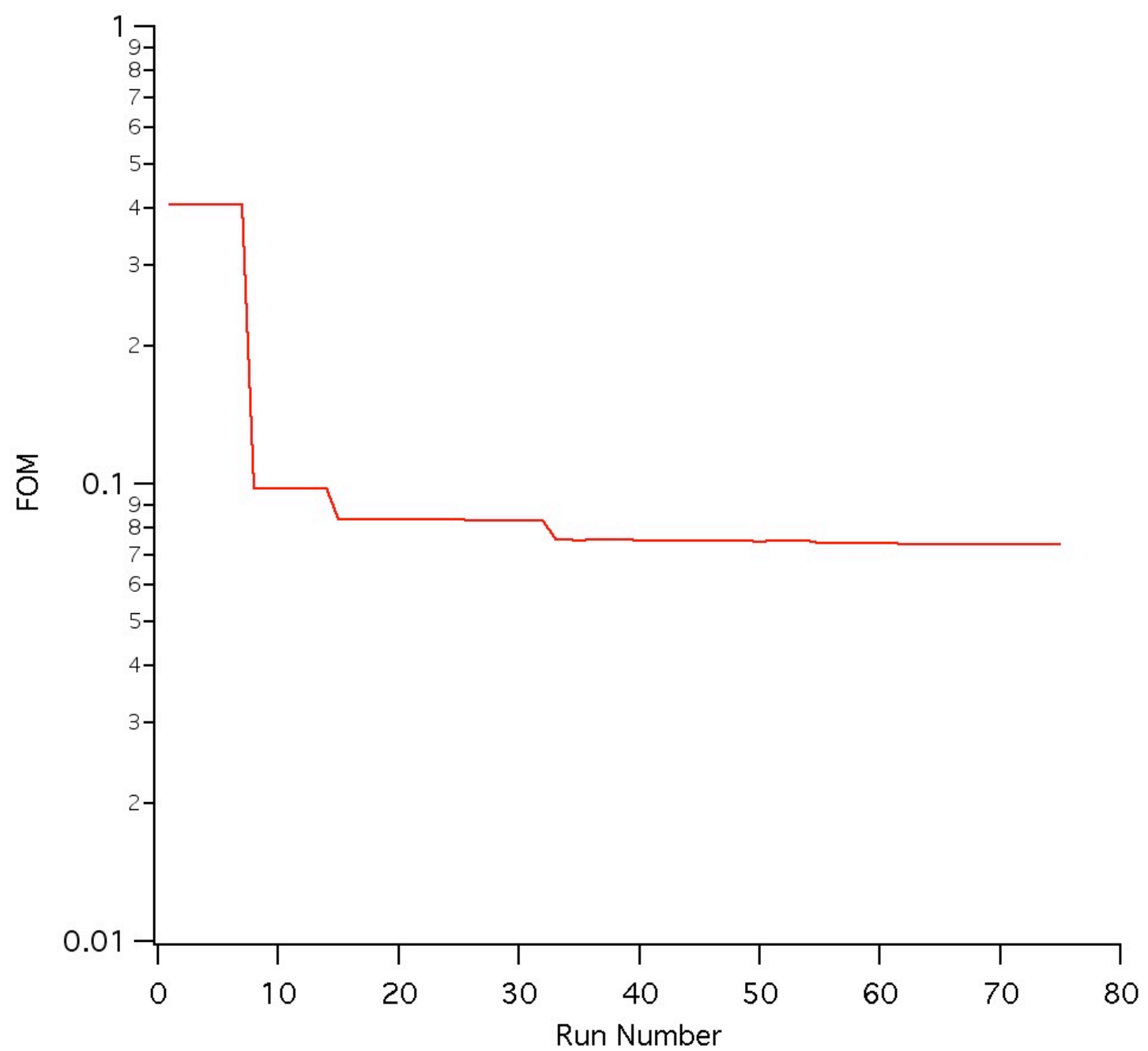

Figure 3. Adjustment of the FOM using MinPack optimization.

\section{Results and Conclusions}

The calibrated parameters for TNT are shown in Table 3. Figure 4 provides a plot comparing the simulated and experimental ODTX data for all data points. The average error is $28 \%$ for the data, which corresponds to a calculated FOM of 0.093 per Eq. (3) except the averaging is done over all points. For comparison, Figure 4 also provides results for the application of the two-point calibration technique [3], which gives an average error of $23 \%$ and a calculated FOM of 0.088 . Therefore, the minimum value on the response surface found by PSUADE is not the global minimum. It is anticipated that further discretization of the response surface would allow for determination of the global minimum, although the amount of discretization required is uncertain due to the coupling of Prout-Tompkins parameters. Nevertheless, we have shown that using PSUADE in the described manner does allow for determination of a local minimum that is close to the previously calibrated value. 
Table 3. Calibrated Prout-Tompkins parameters for TNT.

\begin{tabular}{|c|c|c|}
\hline Parameter & Value (PSUADE) & Value (2pt calib [3]) \\
\hline$E / R$ & $21494 \mathrm{~K}$ & $19024 \mathrm{~K}$ \\
\hline$A$ & $4.48 \times 10^{15} \mathrm{~s}^{-1}$ & $7.89 \times 10^{14} \mathrm{~s}^{-1}$ \\
\hline$m$ & 0.646056 & 1.0 \\
\hline$n$ & 1.94178 & 0.0 \\
\hline$p$ & 4.79118 & 9.0 \\
\hline
\end{tabular}

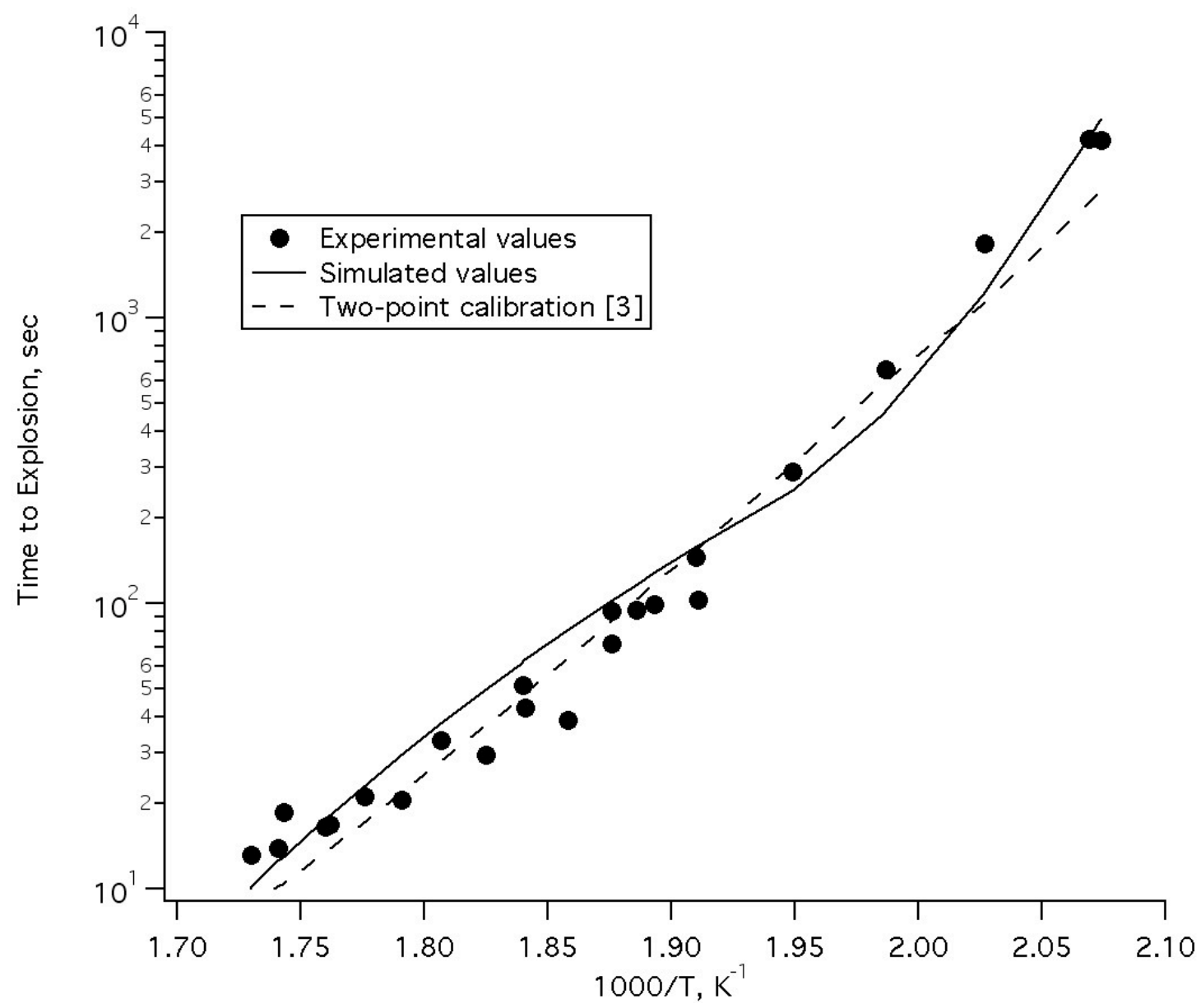

Figure 4. Simulated and experimental ODTX values.

We have shown that PSUADE can be a useful tool to calibrate parameters for in empirical models. In order for this optimization to be useful, however, the following needs to be true:

- The simulation code (such as ALE3D) used must have a text input deck and can run without a GUI.

- The users must have knowledge of Perl or Python (or any general regular expression language) to create the appropriate script to run a series of codes. 
UCRL-TR-230194

- The code should be available to be run on OCF since batch submission is used. The simulations shown here were run on yana.llnl.gov.

\section{References}

1. Murphy, M. J., 1999, GLO - Global Local Optimizer User's Manual, Report UCRL-MA-133858, Lawrence Livermore National Laboratory.

2. Wemhoff, A. P., Burnham, A. K., and Nichols, A. L., 2007, The Application of Global Kinetic Models to HMX Beta-Delta Transition and Cookoff Processes, $J$. Phys. Chem. A., Vol. 111, pp. 1575-1584.

3. Wemhoff, A. P., and Burnham, A. K., 2006, Calibration Methods for ODTX Chemical Kinetics for Various Explosives, Report UCRL-TR-222032, Lawrence Livermore National Laboratory.

4. Wemhoff, A. P., Burnham, A. K., Nichols III, A. L., Knap, J., 2006, Calibration Methods for the Extended Prout-Tompkins Chemical Kinetics Model and Derived Cookoff Parameters for RDX, HMX, LX-10 and PBXN-109, Report UCRLCONF-226426, Lawrence Livermore National Laboratory.

5. Hsieh, H., 2006, Application of the PSUADE Tool for Sensitivity Analysis of an Engineering Simulation, Report CODTU-2006-0029, Lawrence Livermore National Laboratory.

6. Burnham, A. K., Weese, R. K., and Weeks, B. L., 2004, A Distributed Activation Energy Model of Thermodynamically Inhibited Nucleation and Growth Reactions and Its Application to the b-d Phase Transition of HMX, J. Phys. Chem. B, Vol. 108, pp. 19432-19441.

7. Catalano, E., McGruire, R., Lee, E., Wrenn, E., Ornellas, D., and Walton, J., 1976, The Thermal Decomposition and Reaction of Confined Explosives, presented at the Sixth Symposium on Detonation.

8. Tran, T. D., Simpson, L. R., Maienschein, J., and Tarver, C., 2001, Thermal Decomposition of Trinitrotoluene (TNT) with a New One-Dimensional Time to Explosion (ODTX) Apparatus, presented at the 32nd International Annual Conference of Fraunhofer-Institut fur Chemische Technologie (ICT). 
UCRL-TR-230194

\section{Appendix A: Contents of PSUADE Input File odtxrun}

PSUADE

INPUT

$\begin{array}{llll}\text { dimension }=5 & & \\ \text { variable } 1 \mathrm{erx}= & 1.00000000 \mathrm{e}+04 & 7.00000000 \mathrm{e}+04 \\ \text { variable } 2 \mathrm{zrx}= & 1.00000000 \mathrm{e}+00 & 4.00000000 \mathrm{e}+01 \\ \text { variable } 3 \mathrm{~m}= & 0.00000000 \mathrm{e}+00 & 2.00000000 \mathrm{e}+00 \\ \text { variable } 4 \mathrm{n}= & 0.00000000 \mathrm{e}+00 & 2.00000000 \mathrm{e}+00 \\ \text { variable } 5 \mathrm{p}= & 2.00000000 \mathrm{e}+00 & 9.00000000 \mathrm{e}+00\end{array}$

OUTPUT

dimension $=7$

variable 1 fom 1

variable 2 fom2

variable 3 fom 3

variable 4 fom 4

variable 5 fom5

variable 6 fom 6

variable 7 fom 7

END

METHOD

sampling $=$ METIS

END

num_samples $=100$

APPLICATION

END

driver $=$ driver $\cdot$ py

ANALYSIS

diagnostics 2

END

END 
UCRL-TR-230194

\section{Appendix B: Contents of PSUADE Driver File driver.py}

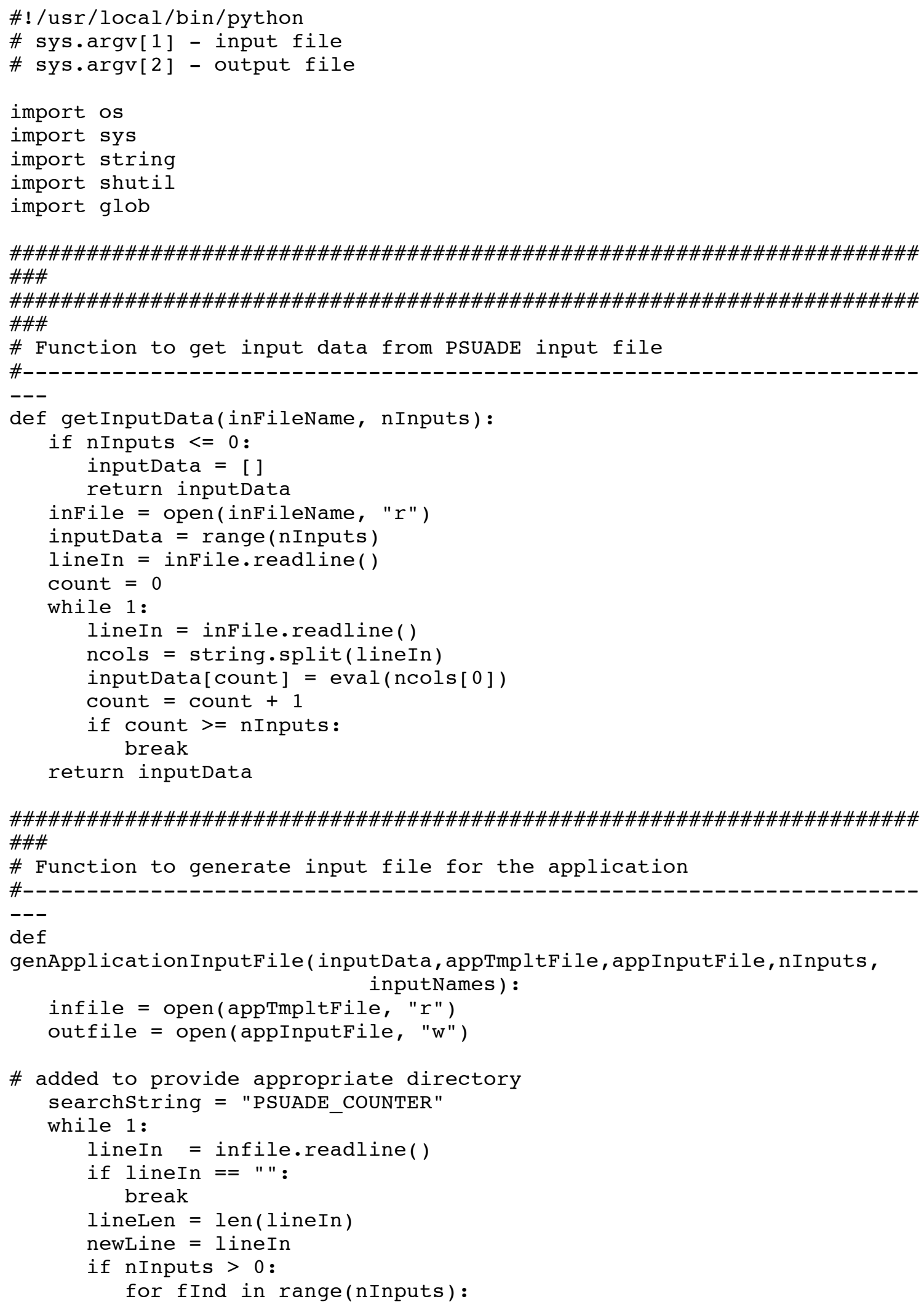


UCRL-TR-230194

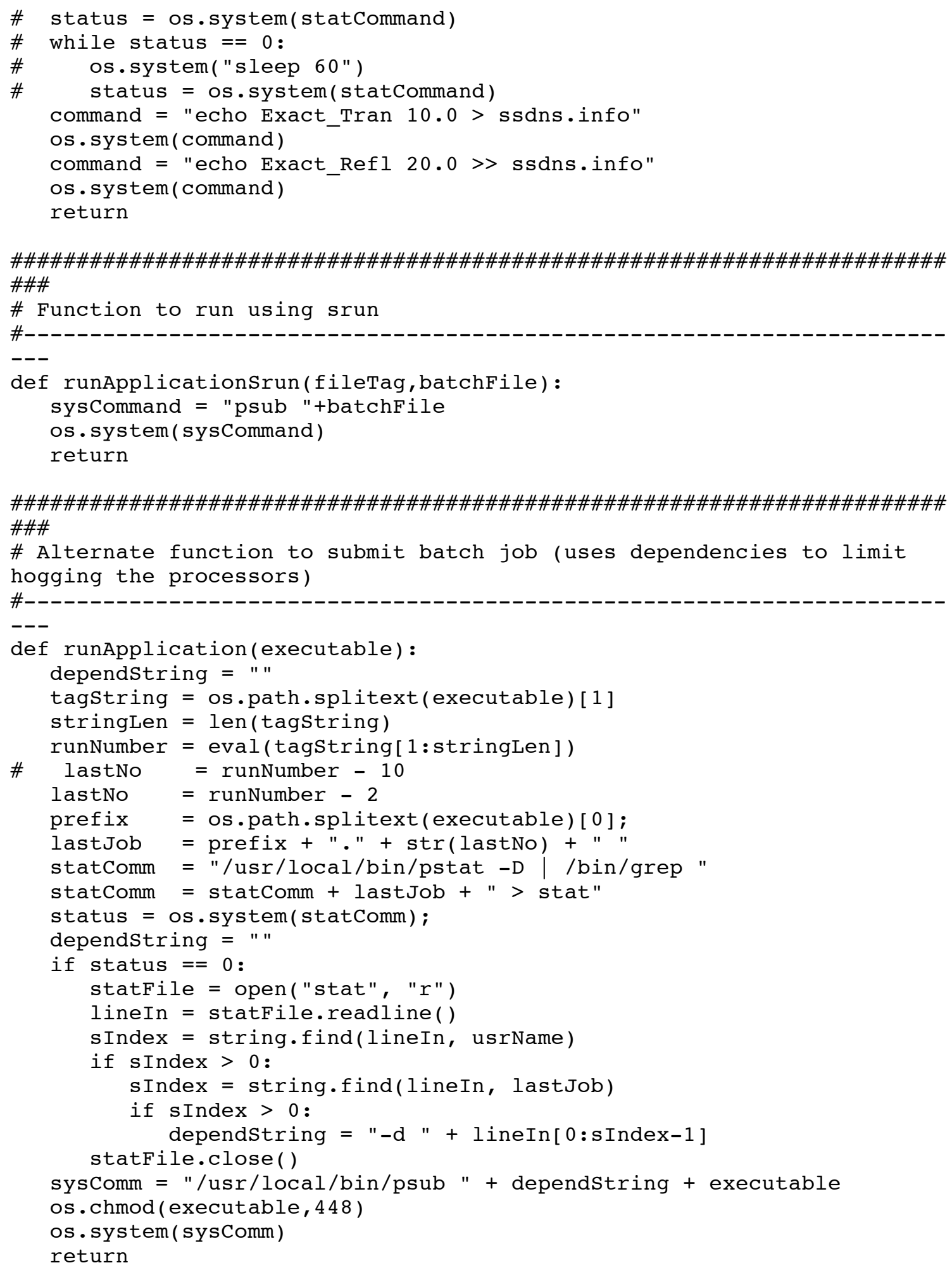

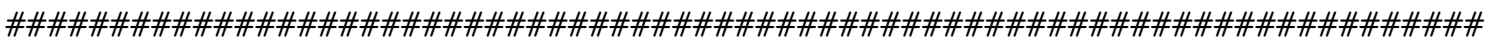
\#\#\#

\# Alternate function to submit batch job (uses dependencies to limit hogging the processors) - APW 
UCRL-TR-230194

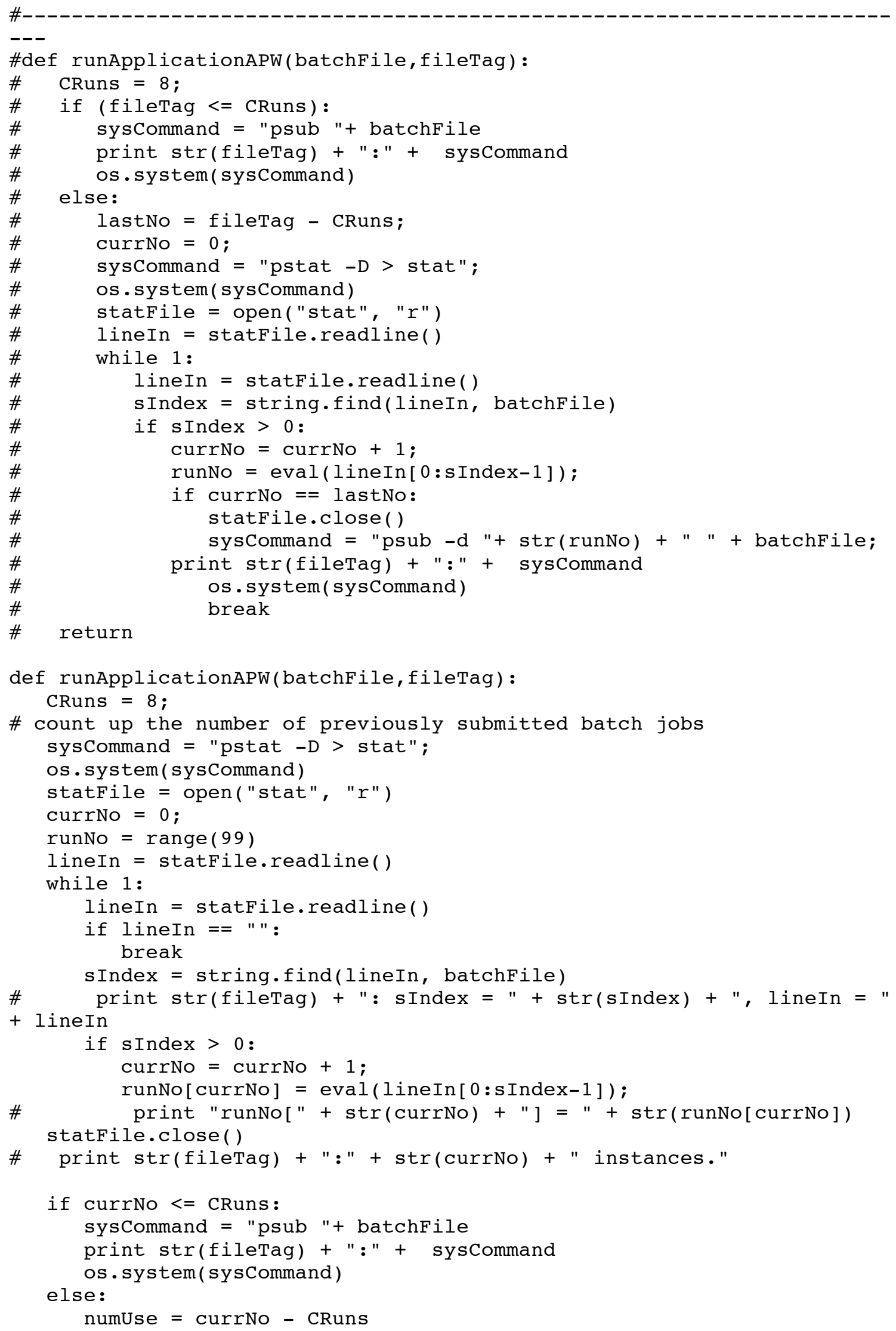


UCRL-TR-230194

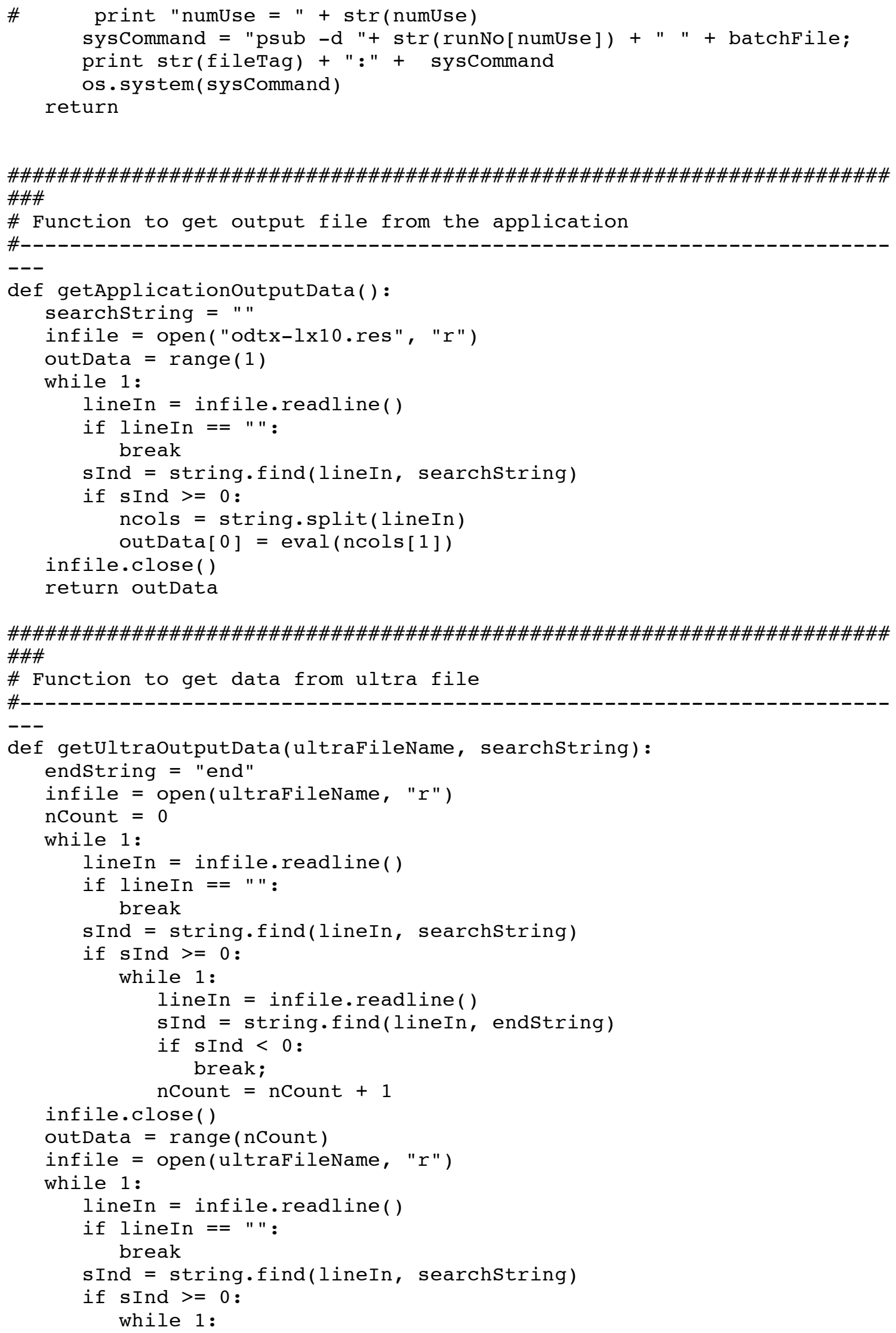


UCRL-TR-230194

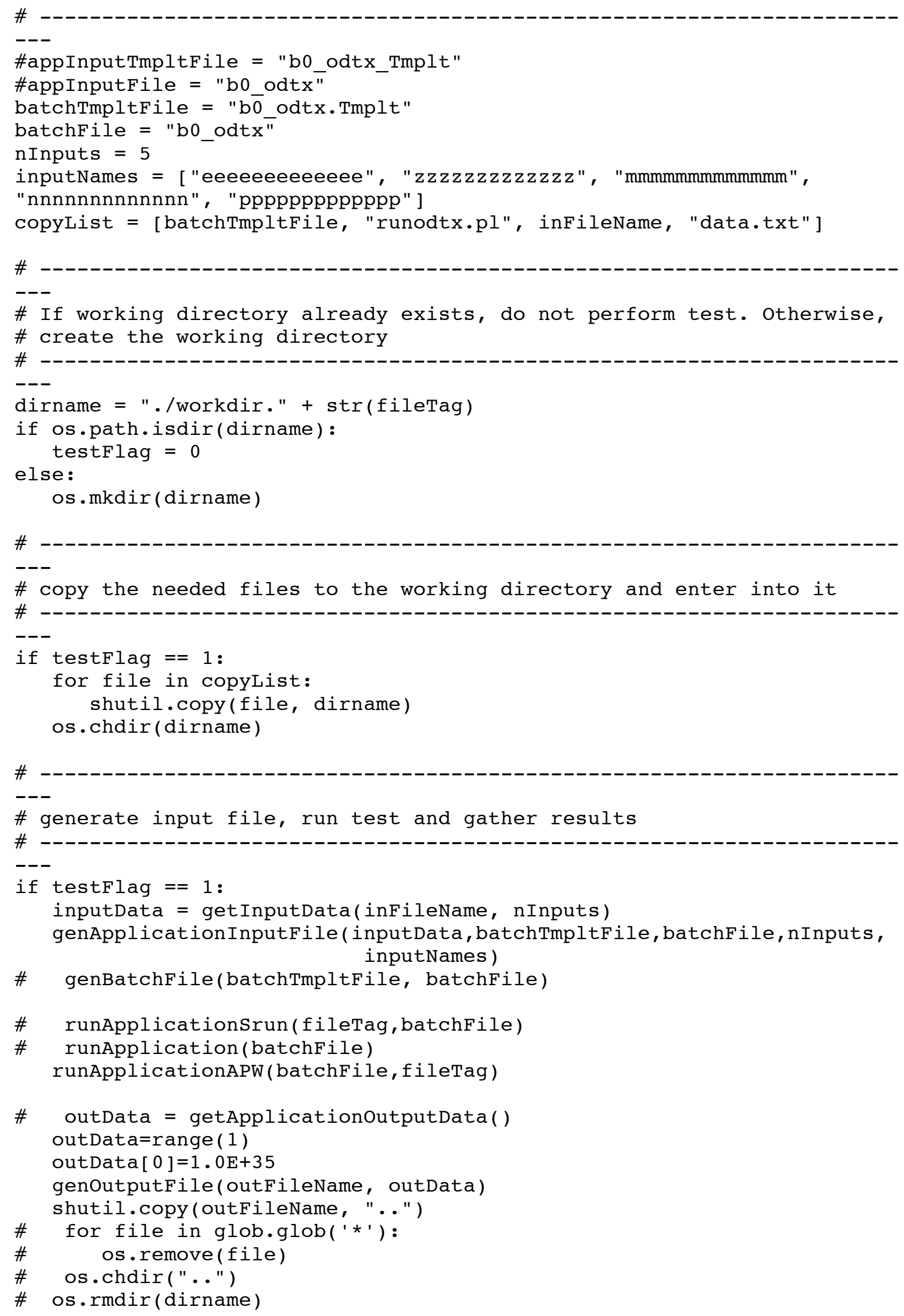


UCRL-TR-230194

\section{Appendix C: Contents of Batch Script Template bo_odtx.Tmplt}

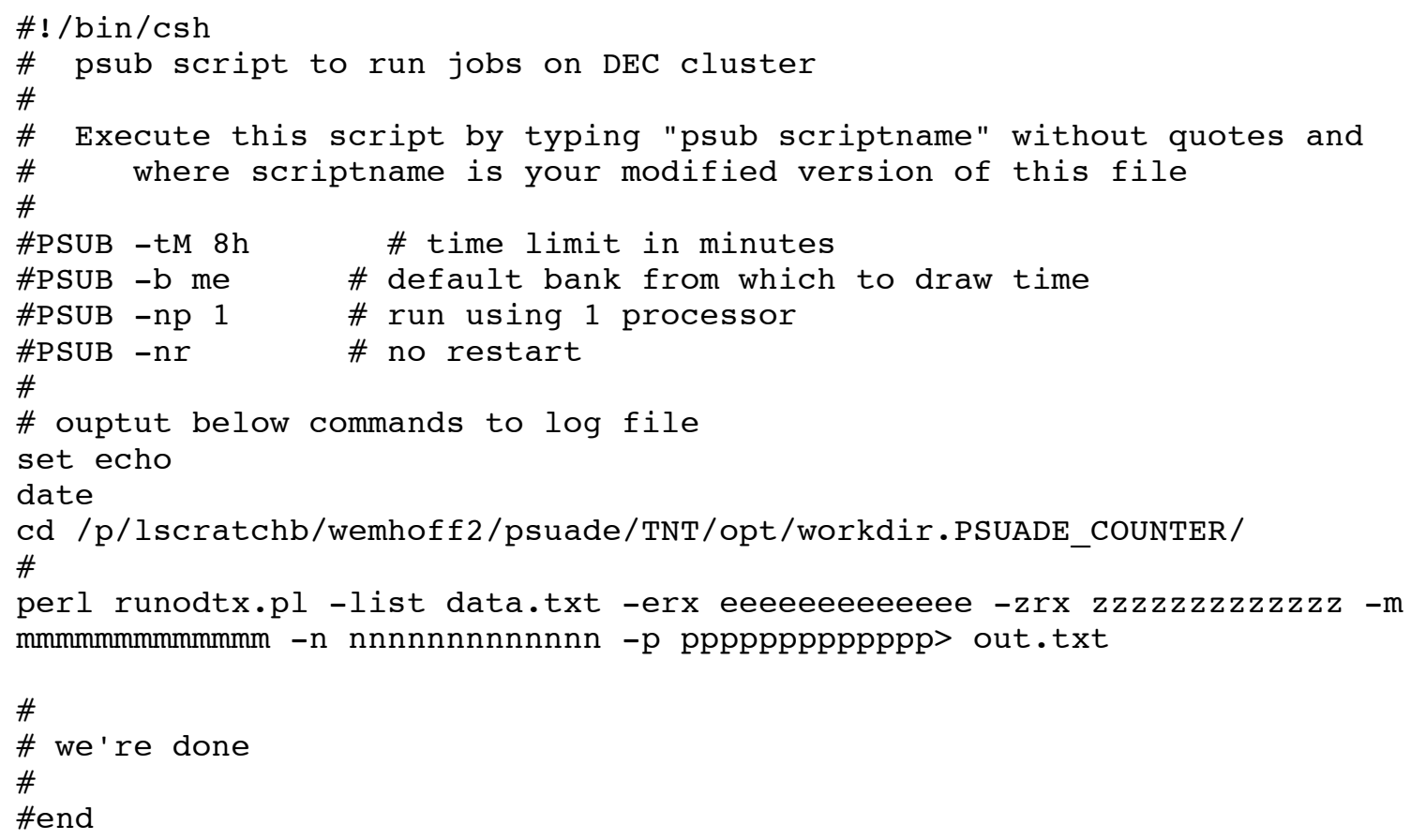


UCRL-TR-230194

\section{Appendix D: Contents of runodtx.p1}

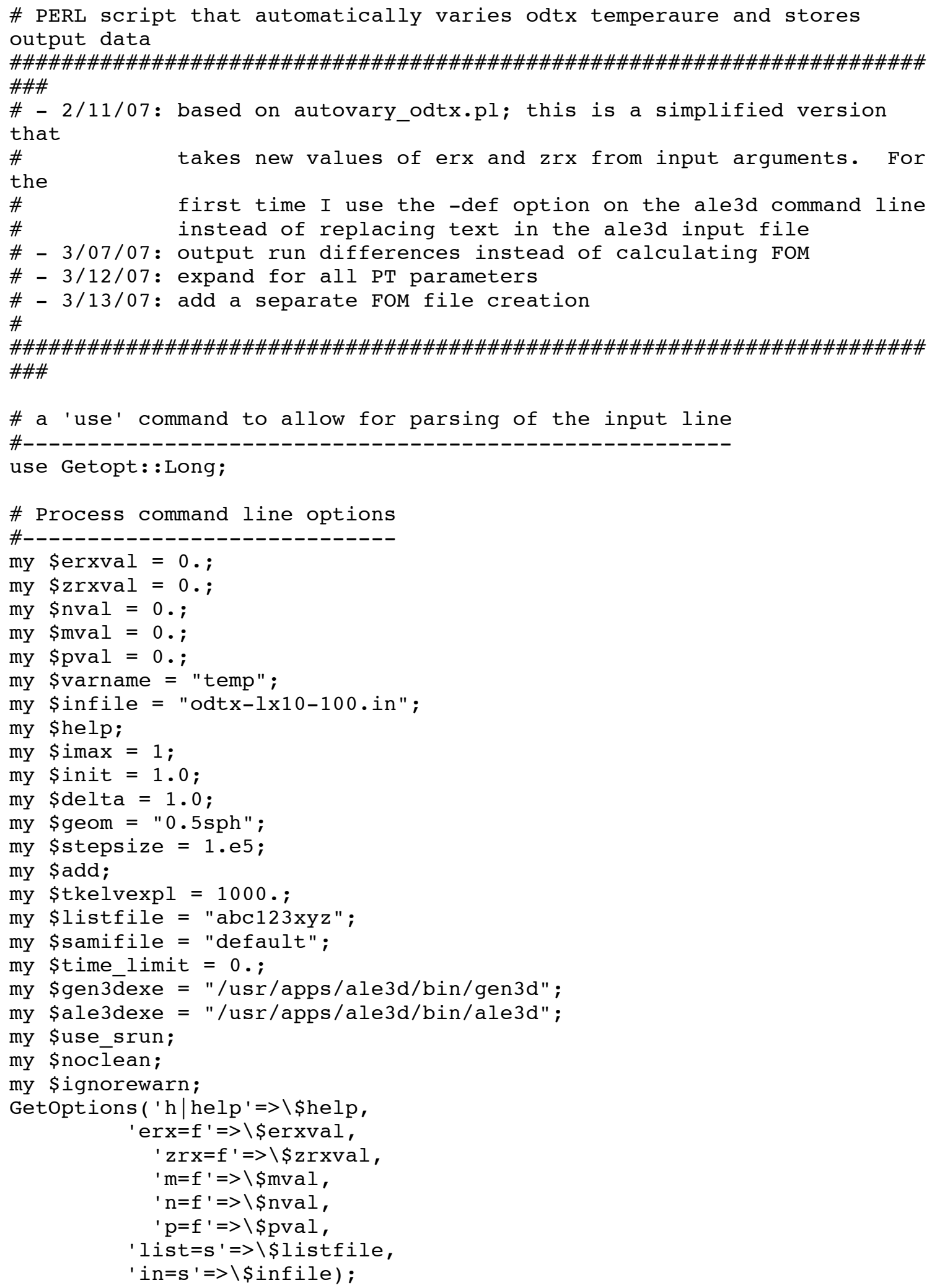


UCRL-TR-230194

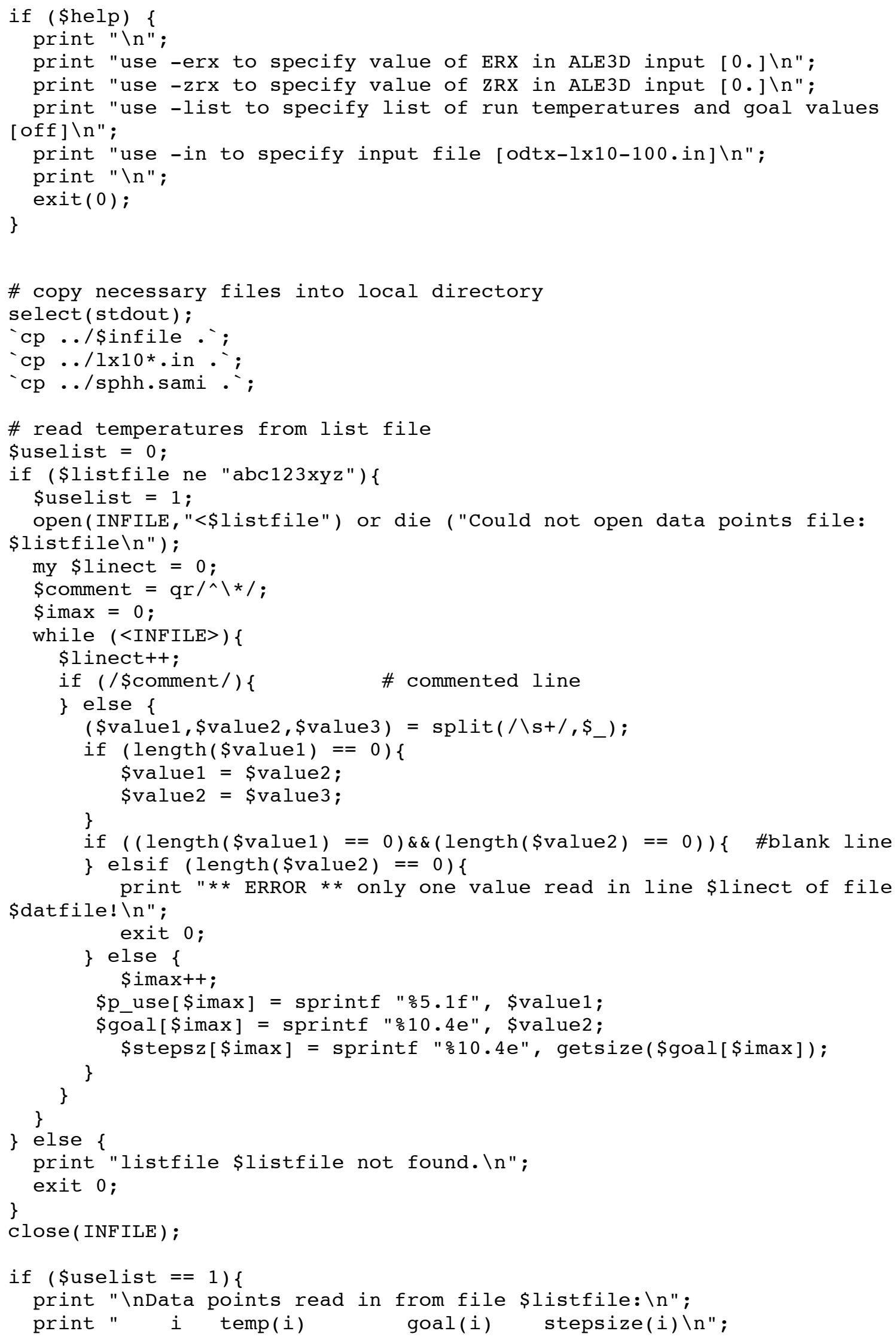


UCRL-TR-230194

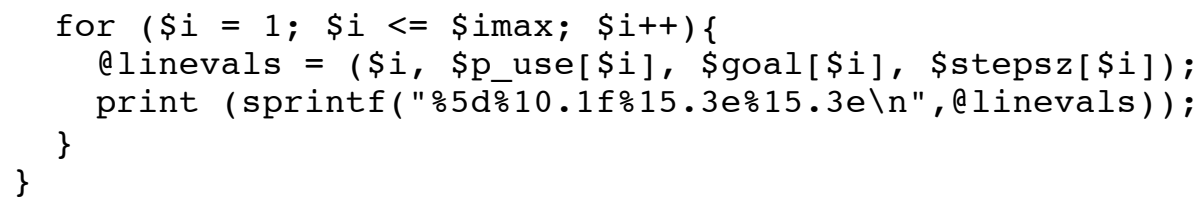


UCRL-TR-230194

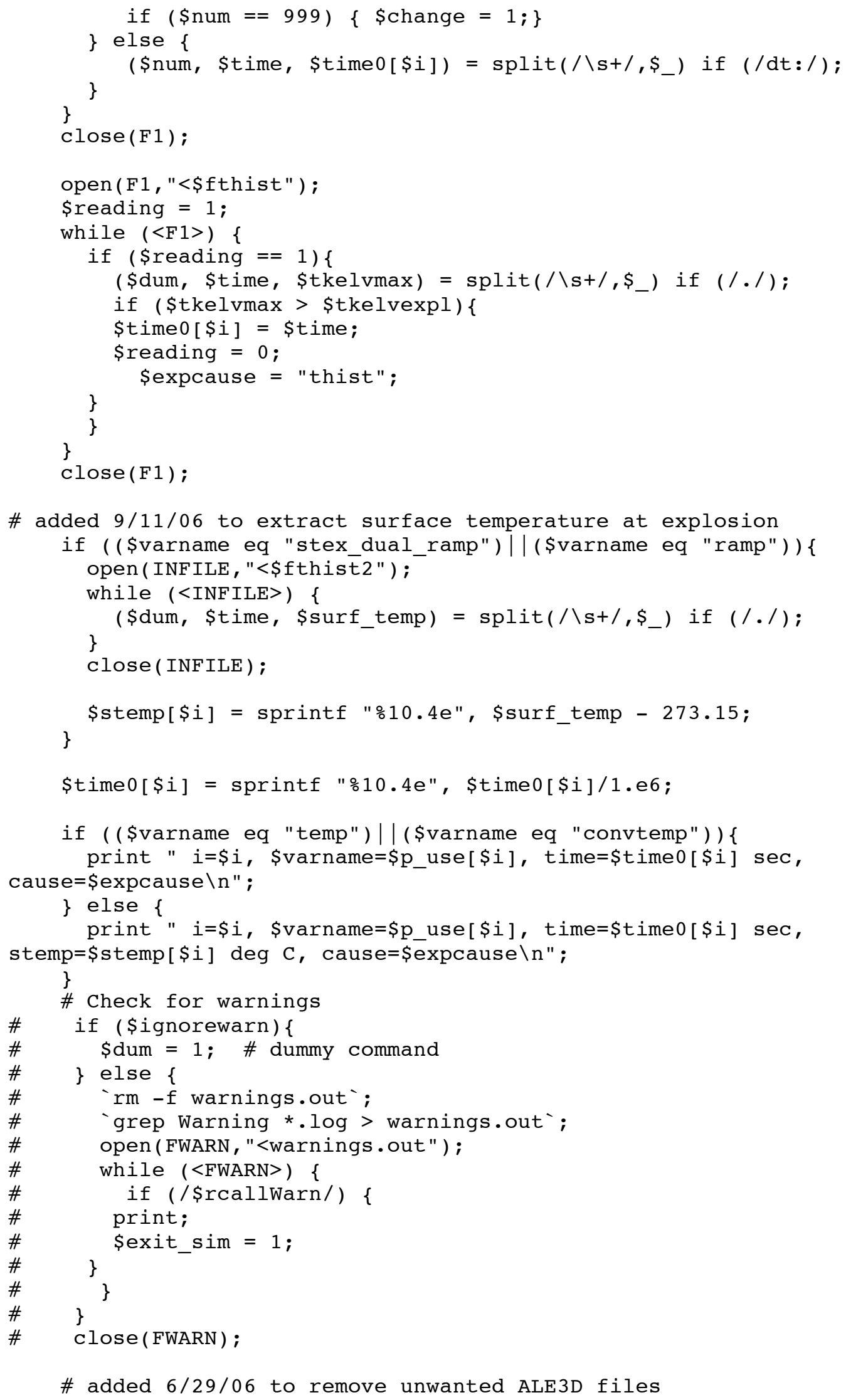


UCRL-TR-230194

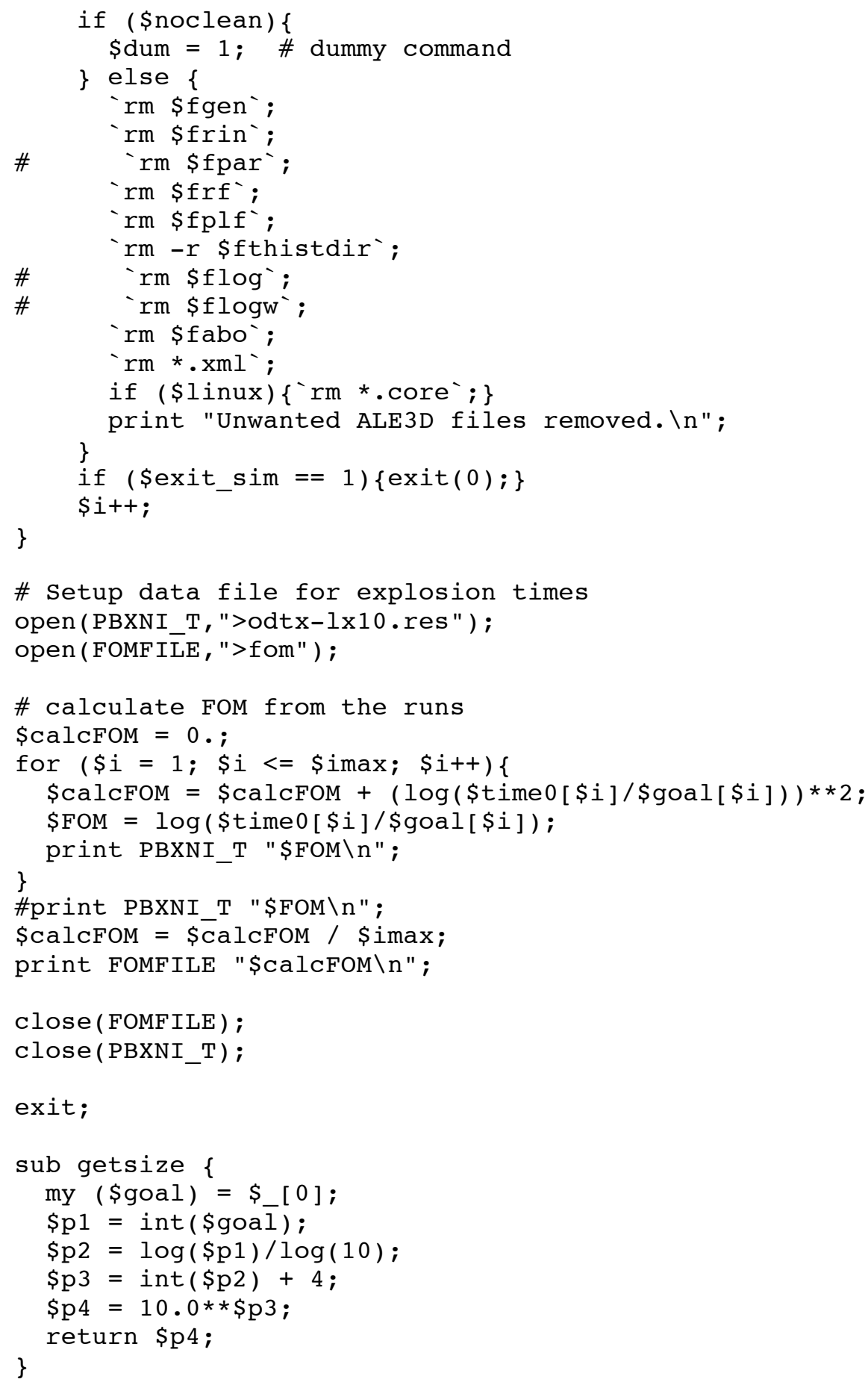


UCRL-TR-230194

\section{Appendix E: Contents of getresults.pl}

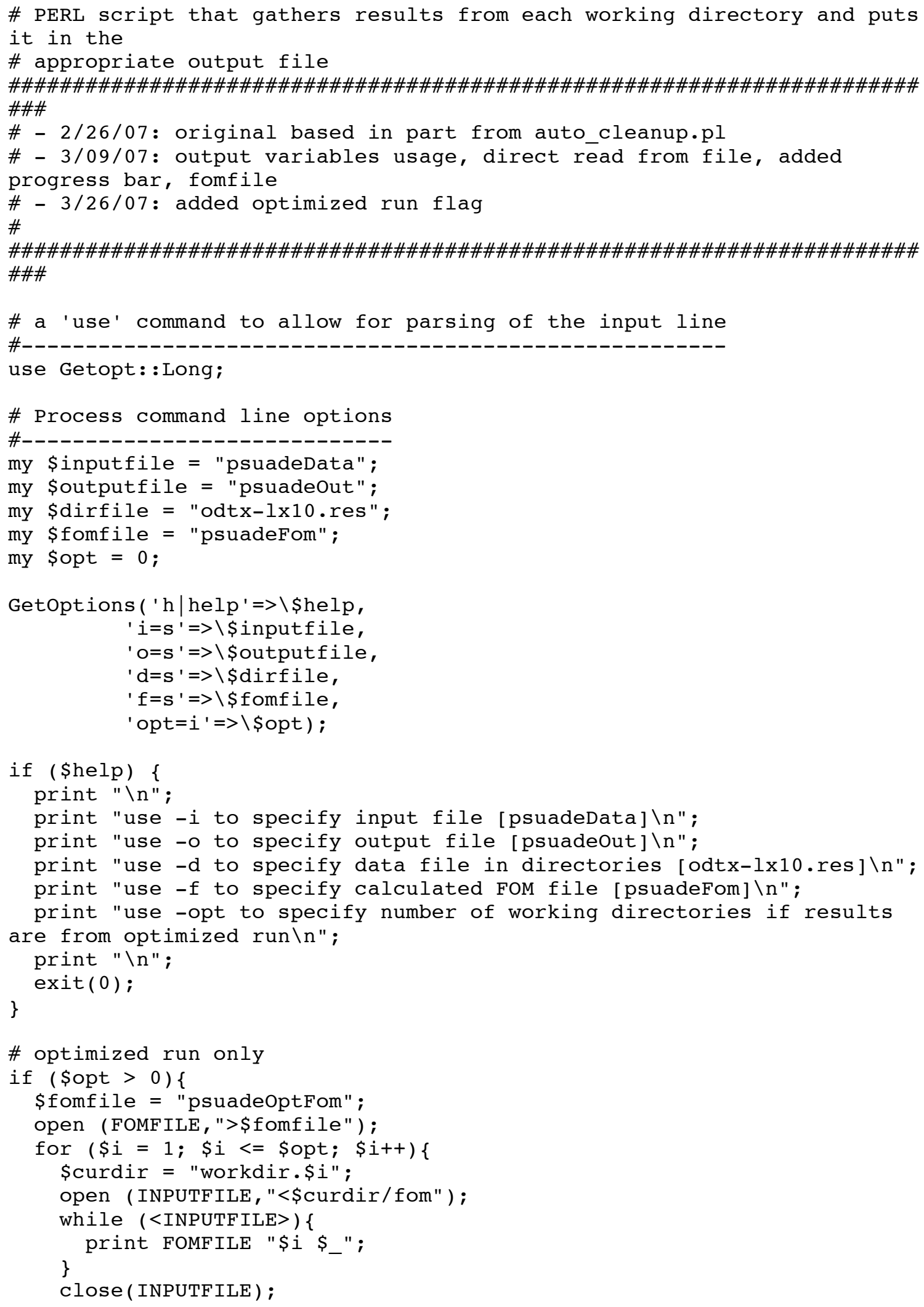


UCRL-TR-230194

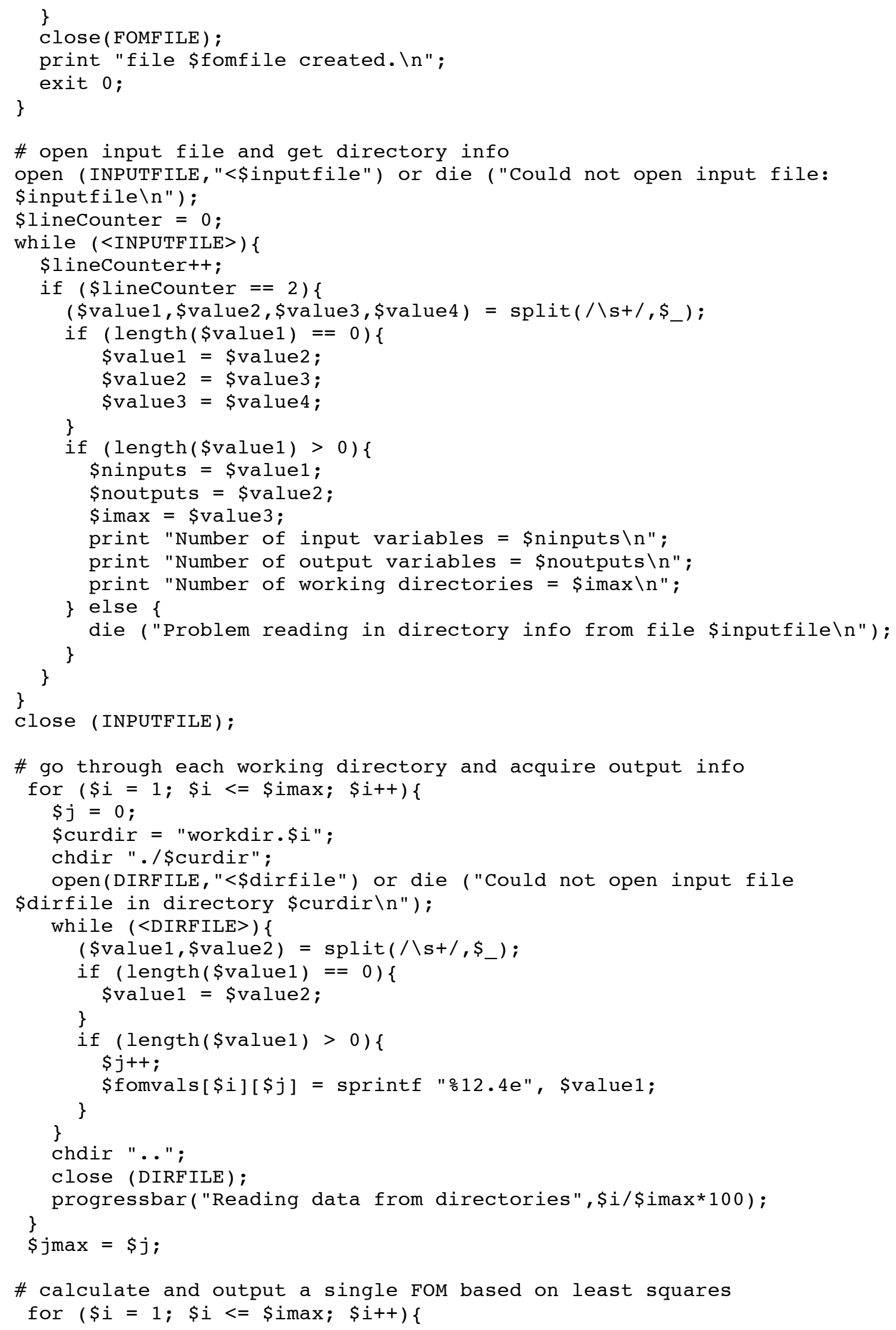


UCRL-TR-230194

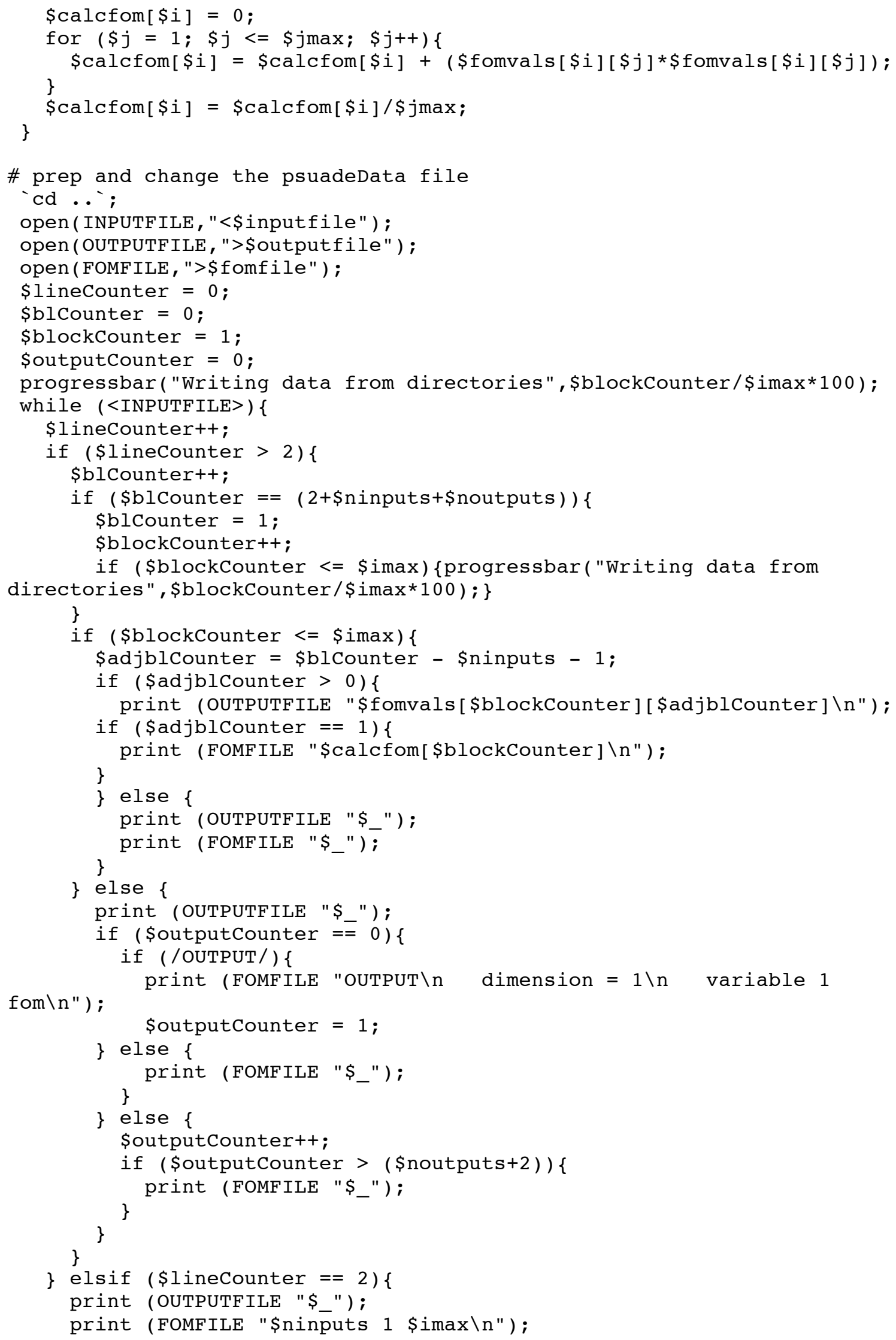


UCRL-TR-230194

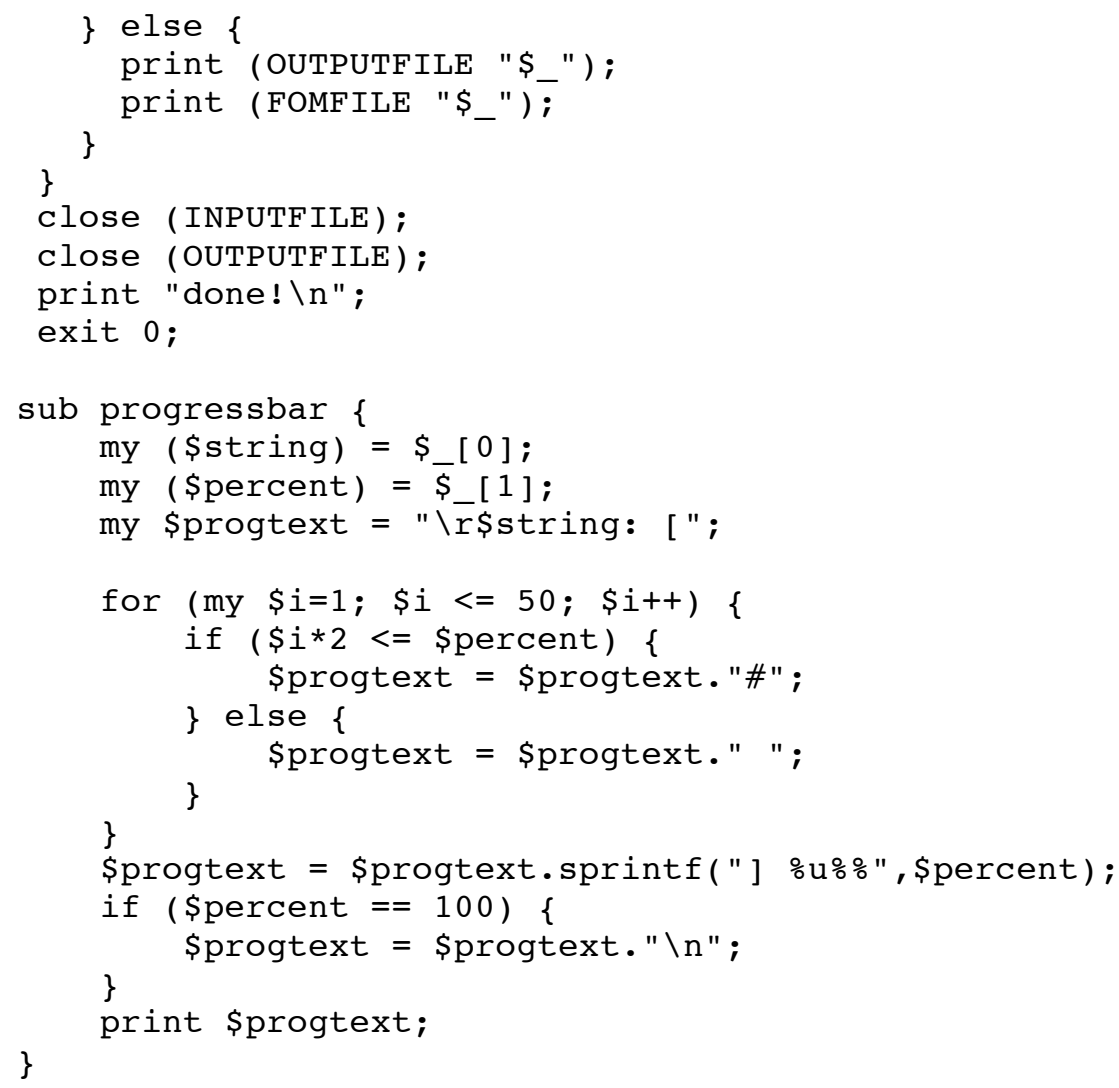


UCRL-TR-230194

\section{Appendix F: Contents of PSUADE Input File odtxoptMinpack}

PSUADE_IO (Note : inputs not true inputs if pdf $\sim=U$ )

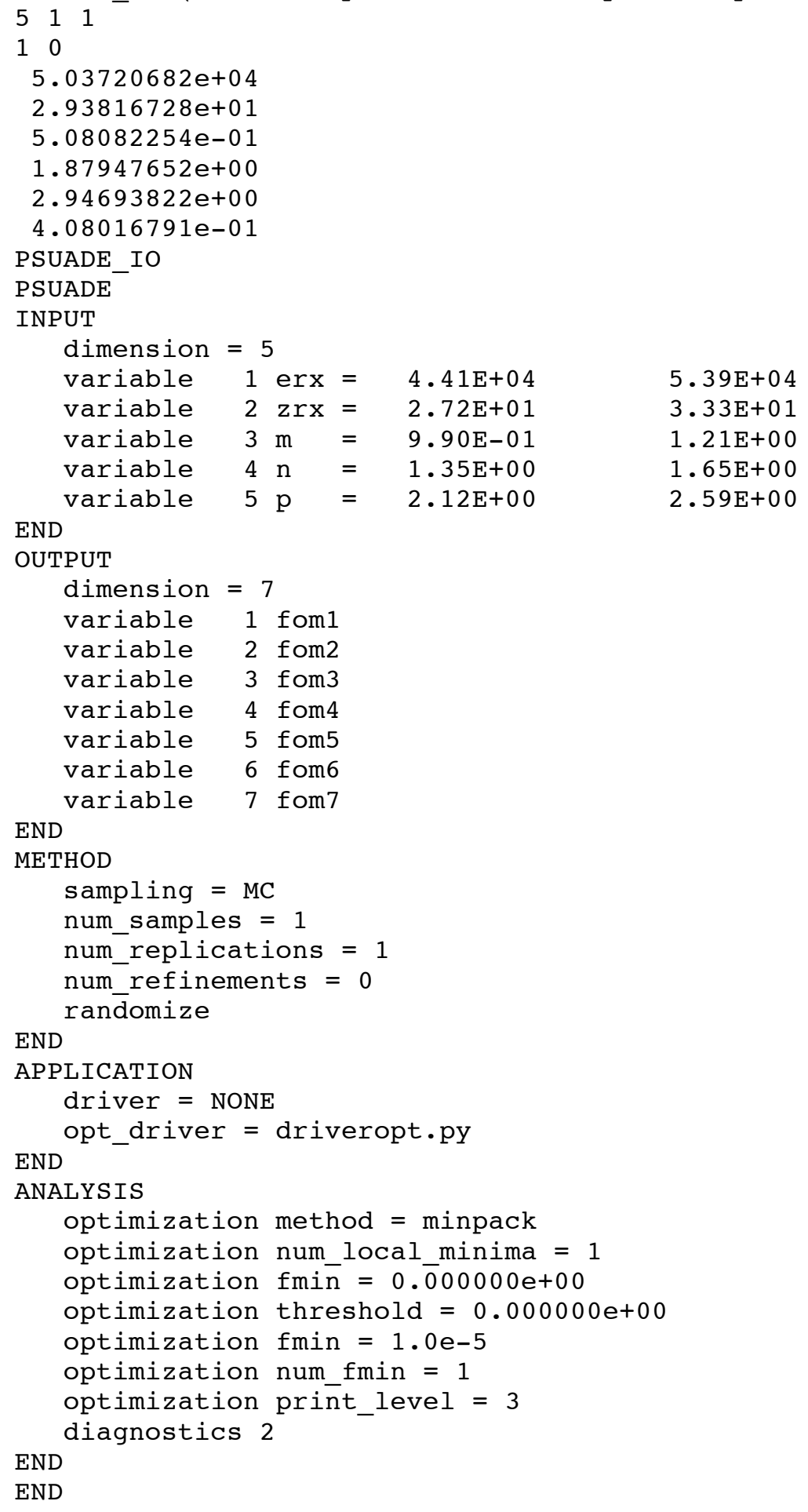


UCRL-TR-230194

\section{Appendix G: Contents of PSUADE Driver File driveropt.py}

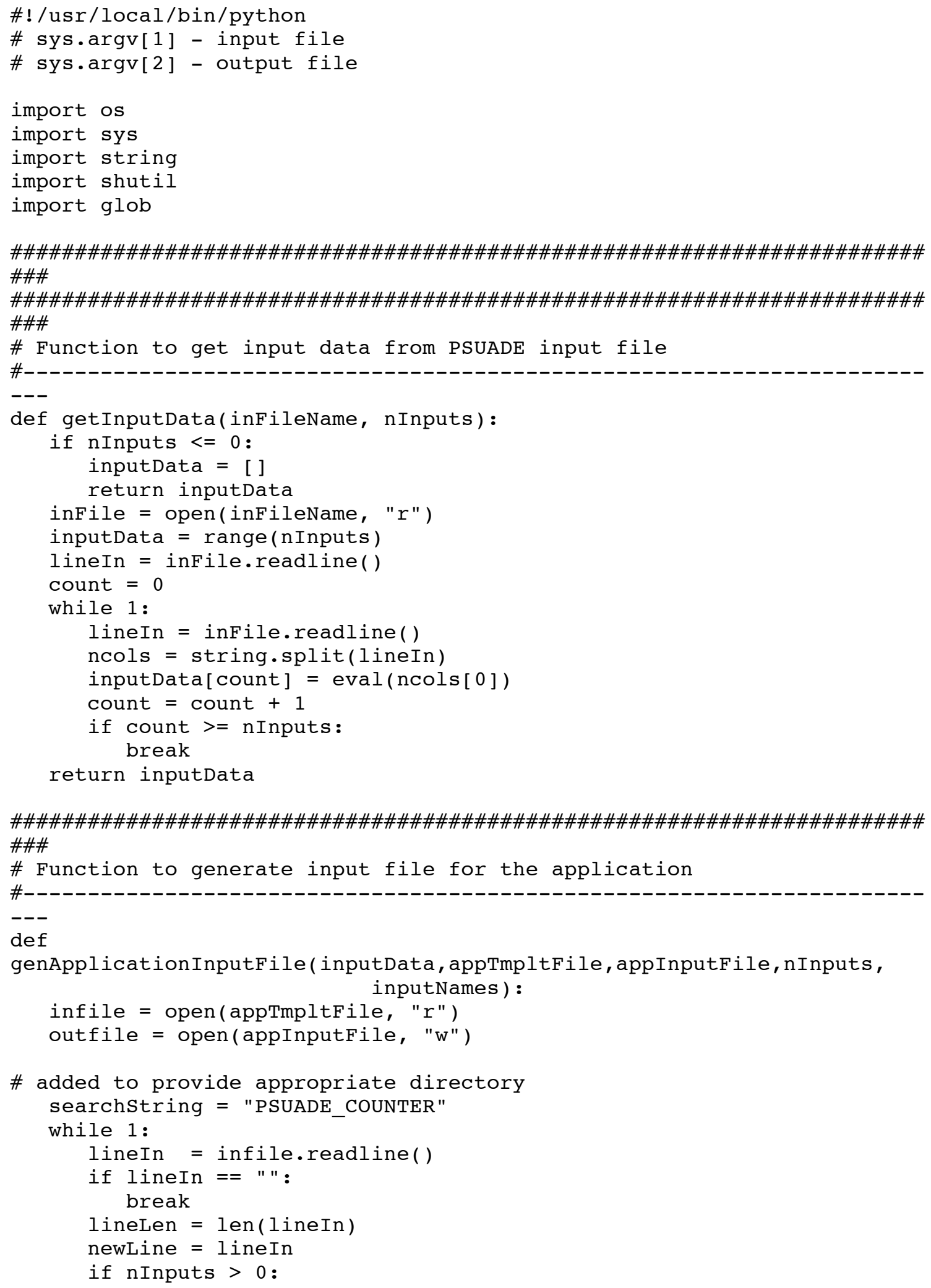


UCRL-TR-230194

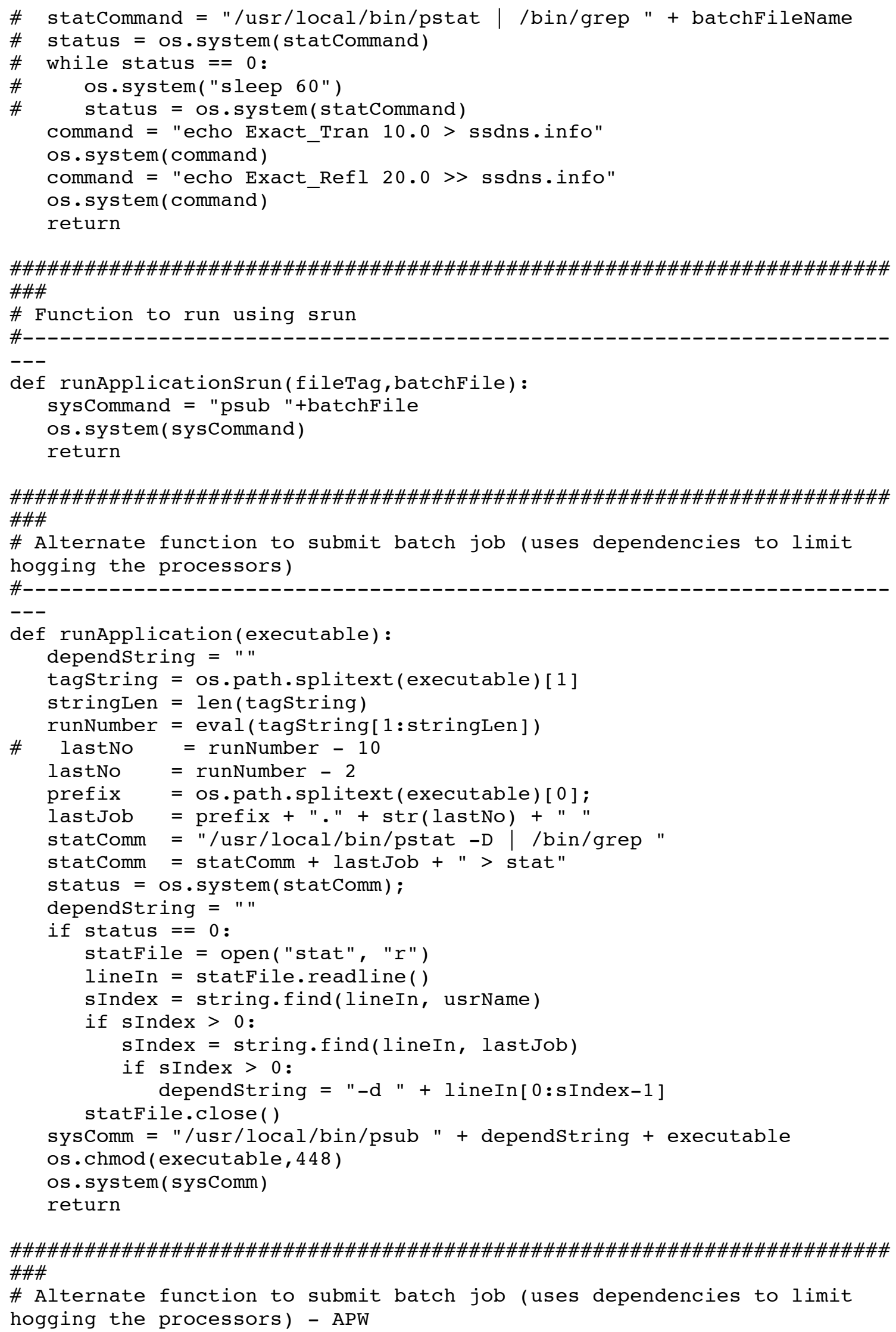

\#\#\#\#\#\#\#\#\#\#\#\#\#\#\#\#\#\#\#\#\#\#\#\#\#\#\#\#\#\#\#\#\#\#\#\#\#\#\#\#\#\#\#\#\#\#\#\#\#\#\#\#\#\#\#\#\#\#\#\#\#\#\#\#\#\#\#\# \#\#\#

\# Alternate function to submit batch job (uses dependencies to limit hogging the processors) - APW 
UCRL-TR-230194

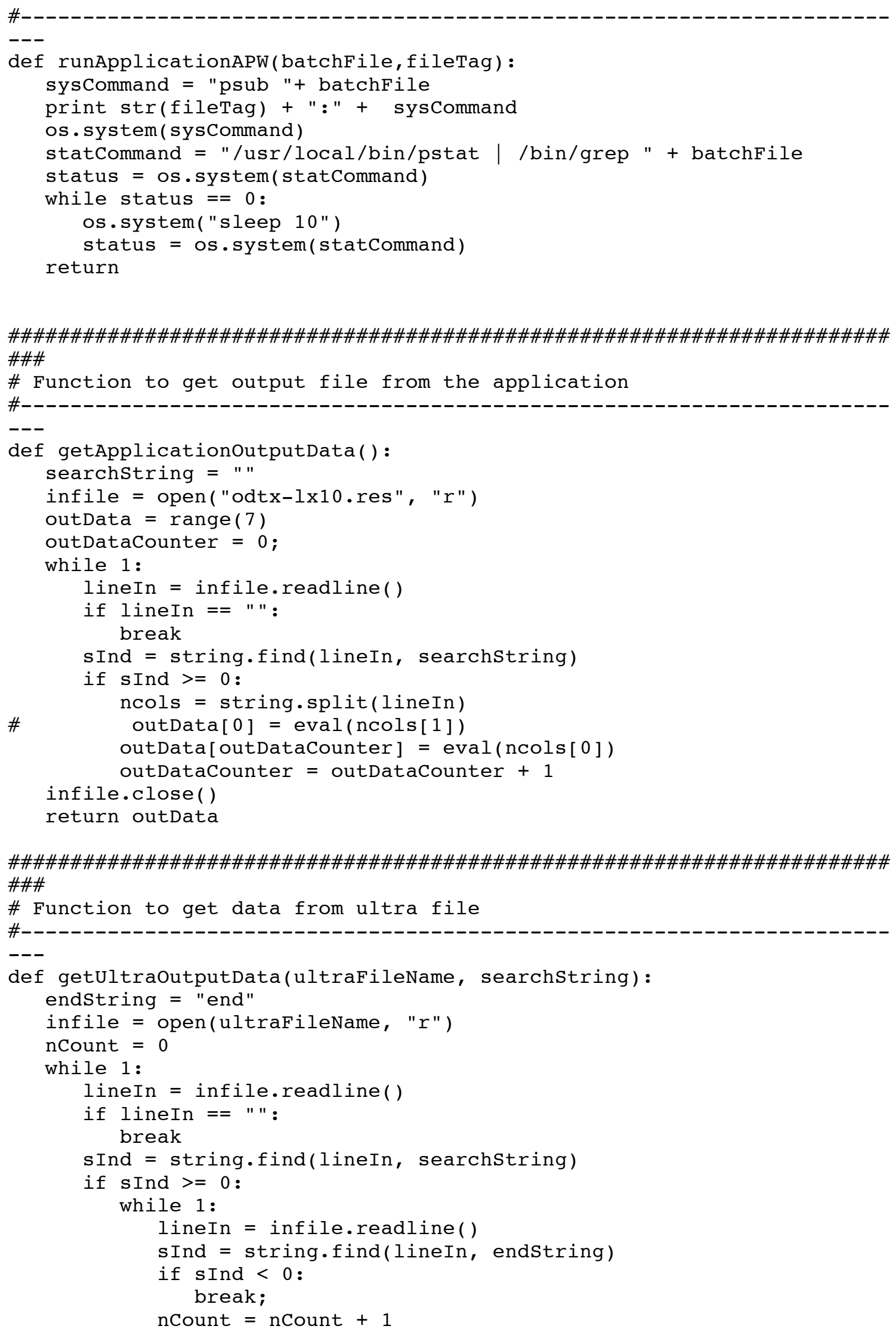


UCRL-TR-230194

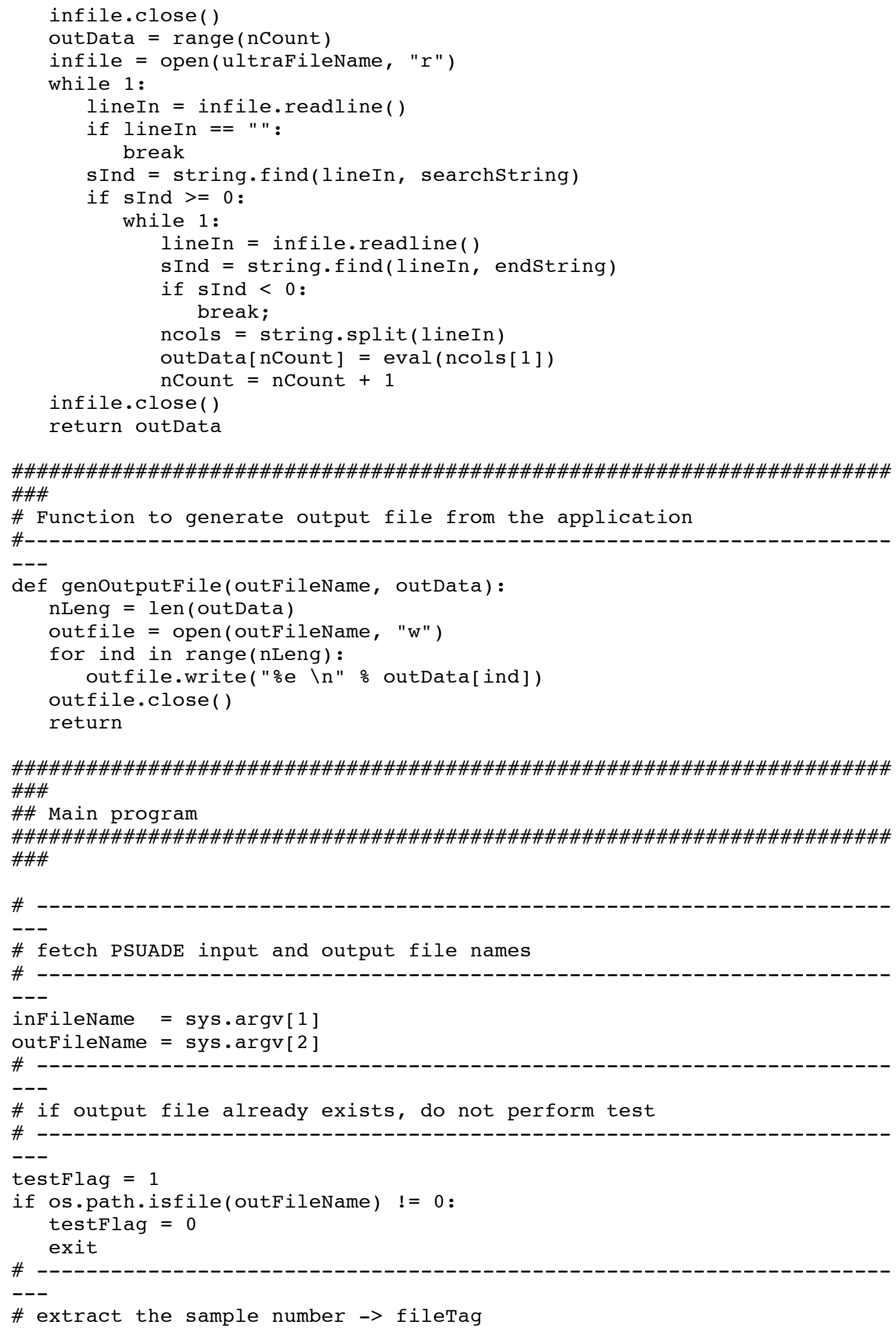


UCRL-TR-230194

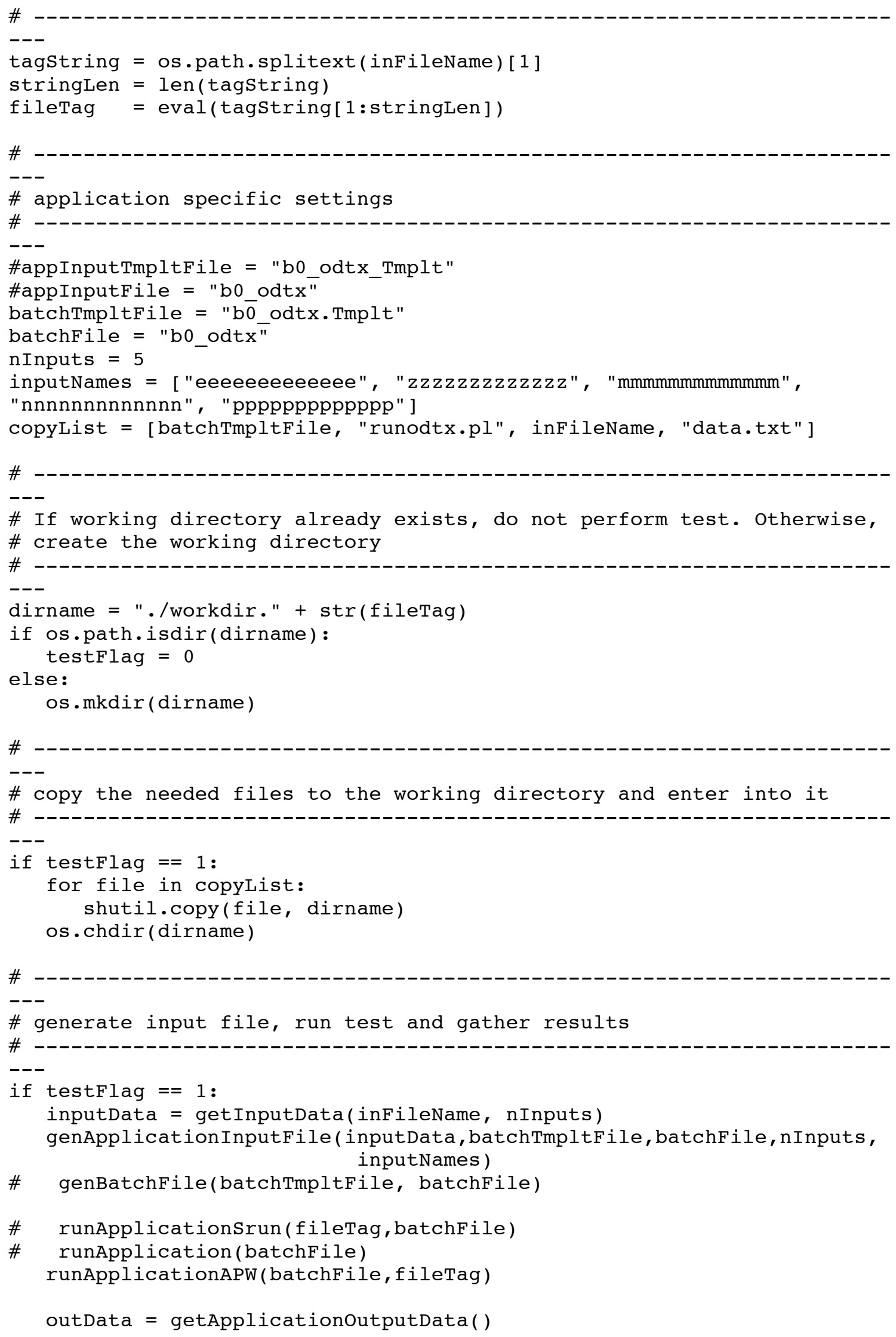


UCRL-TR-230194

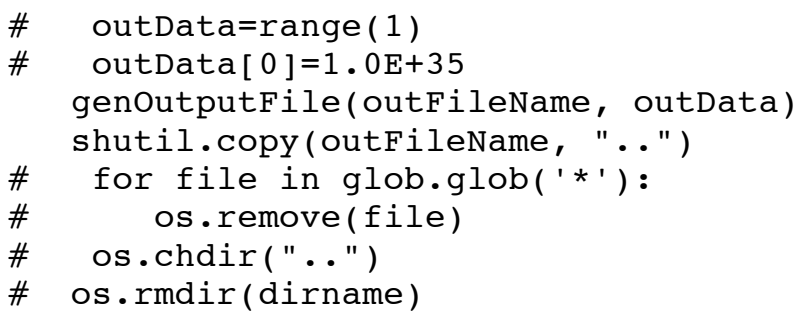

